Insciences J. 2011, 1(1), 30-64; doi:10.5640/insc.010130

Review Paper

\title{
Realistic Exposure Methods for Investigating the Interaction of Nanoparticles with the Lung at the Air-Liquid Interface In Vitro
}

\author{
Loretta Müller $^{1}$, Michael Gasser ${ }^{1,2}$, David O. Raemy ${ }^{1,2}$, Fabian Herzog ${ }^{1,2}$, Christina \\ Brandenberger $^{1,3}$, Otmar Schmid ${ }^{4}$, Peter Gehr ${ }^{1}$, Barbara Rothen-Rutishauser ${ }^{1,2}$ and \\ Martin J.D. Clift ${ }^{12^{*}}$
}

1 Institute of Anatomy, University of Bern, Baltzerstrasse 2, CH-3000, Bern 9, Switzerland.

2 Department of Clinical Research, Division of Pneumology, Inselspital University Hospital, University of Bern, Murtenstrasse 50, Bern 3010, Switzerland

3 Lung Biology Laboratory, Department of Medicine, Columbia University, 630 West, 168 Street 10032 New York, USA.

4 Comprehensive Pneumology Centre, Institute of Lung Biology and Disease, Helmholtz Zentrum München, Neuherberg, Germany

* Author to whom correspondence should be addressed; Martin J.D.Clift; Tel.: +41-316318-490; Fax: +41-316-313-807, E-Mail: martin.clift@ana.unibe.ch

Received: 02 November 2010 / in revised form: 04 January 2011 / Accepted: 28 January 2011 / Published: 08 February 2011

\begin{abstract}
In light of the increasingly abundant use of engineered nanoparticles (NPs) and the ongoing exposure to ambient ultrafine particles it is imperative that the potential for NPs to elicit adverse effects on human health is understood. In order to determine the potential harm that NPs may exert, many different in vitro systems have been used. Commonly in vitro nanotoxicology studies use NP suspensions applied directly to cell cultures. Although the use of in vitro monoculture systems to assess the effects of NPs on, for example, the lung is frequently debated, the use of suspension exposures is not realistic in relation to the exposure of NPs to humans via inhalation; the primary
\end{abstract}


exposure route to the human body for NPs. As an alternative to the suspension (or submerged) exposure method, numerous different exposure systems at the air-liquid interface have been developed and used in nanotoxicology research, which mimic the realistic conditions of NP inhalation exposure. In addition, such air-liquid exposure systems also offer the advantage to determine the exact dose (or concentration) which is deposited on the cell surface. The aim of this review is to provide a description of these different exposure systems, to explain how they recreate realistic inhalation conditions for occupational and environmental exposure, as well to describe how they may be used to gain an insight into how NPs may interact with the epithelial airway barrier following inhalation.

Keywords: nanoparticles; nanotoxicology; exposure routes; lung; epithelial airway barrier; inhalation; exposure methods; exposure systems; air-liquid interface

\section{Introduction:}

Nanotechnology intends to provide numerous advantages to industrial, technological and consumer applications (1). The unique physicochemical properties of nanomaterials however, have raised concerns as to their ability to cause adverse human health effects (2, $3,4)$. In order to gain an understanding of the potential adverse effects that may be associated with exposure to nanomaterials, or nanoparticles (NPs), the field of nanotoxicology, or nanoscience (5), has significantly grown over the past ten years. This is notable from the increasing number of studies published investigating the effects of the NPs on different organs, either in vivo or in vitro, over the past ten years (6). For example, in the year 2000, 224 original/review papers were published, whilst in year 2010, 4815 original/review papers were published (statistics obtained from www.sciencedirect.com on 24th September 2010 using the keywords 'nano' and 'health effects' in all fields).

The characteristics of NPs are unique (7). Although many characteristics have been highlighted as driving the potential adverse health effects associated with NP exposure (8), it has been specifically the size and increased surface area of NPs that has been concluded as elucidating any such adverse effects observed $(9,10,11,12,7,4)$. Due to the plethora of NPs being produced in various forms (e.g. spherical, fibres, rods, clusters) or by different processes (e.g. flame-spray synthesis, chemical vapour deposition), defining the characteristics of a NP has provided the basis for increased discussion and 
governmental initiatives (such as $\operatorname{SCHENIR~}(13,14)$ and NanoImpactNet (www.nanoblog.ch)) to determine exactly how NPs may be defined (15). For the purposes of this review, a NP is understood to be a nano-object (a material with one, two or three external dimensions in the nanoscale $(1-100 \mathrm{~nm})$ ) with all three external dimensions in the nanoscale (16). For further definitions regarding 'nano', both www.iso.org and the webpage of the EU FP7 project NanoImpactNet (www.nanoblog.ch) are recommended.

The need for the potential for NPs to elicit adverse effects to human health is paramount (17). The lack however, of any form of useful risk assessment for NPs from the published literature has raised concerns. In an attempt to rectify these concerns, numerous factors have been highlighted as essential when performing any study regarding possible NP toxicity (8). An example of this is the need to include detailed NP characterisation in the media/buffer used, such as size, zeta potential, chemical composition and surface chemistry (8). Other aspects of NP toxicology studies that do not receive as much attention as they should are (i) the use of a realistic concentration, or dose, and (ii) how this is then applied to the biological system being studied (18). The aim of this review therefore, is to provide an overview of various different exposure systems which have been constructed to realistically study the potential adverse effects of exposure to NPs (via inhalation) in both occupational and environmental settings.

\section{Discussion:}

\subsection{Human Exposure to NPs}

Due to the many different forms of NPs being produced and used in a wide variety of consumer, industrial and technological applications the exposure routes for which humans may be potentially exposed to NPs are numerous. The specific routes by which NPs may enter the human body, and potentially elicit adverse effects, are understood to include inhalation, injection, ingestion and permeation through (diseased) skin (Fig. 1) $(4,19)$.

The availability and toxicity of any substance to a biological organism is determined by both the concentration/dose that the organism is exposed to, as well as the "toxicokinetics" of the substance. These include the uptake, transport, metabolism and sequestration to different compartments by the organism, as well as the elimination of the substance from the biological organism. These parameters are essential, since the potential toxicity of substances is dependent upon the specific organs or cell types exposed, which form the substance is in (e.g. bound to serum protein, aggregated, dissolved, oxidised), as well as the period of time the substance interacts/remains at the site of primary and secondary exposure. 
Figure 1. Overview of the exposure routes of NPs into the human body and their subsequent fate (adapted from (4)). In this figure, the epidermis is highlighted to denote that only the diseased skin is at risk to NPs, and not healthy skin.

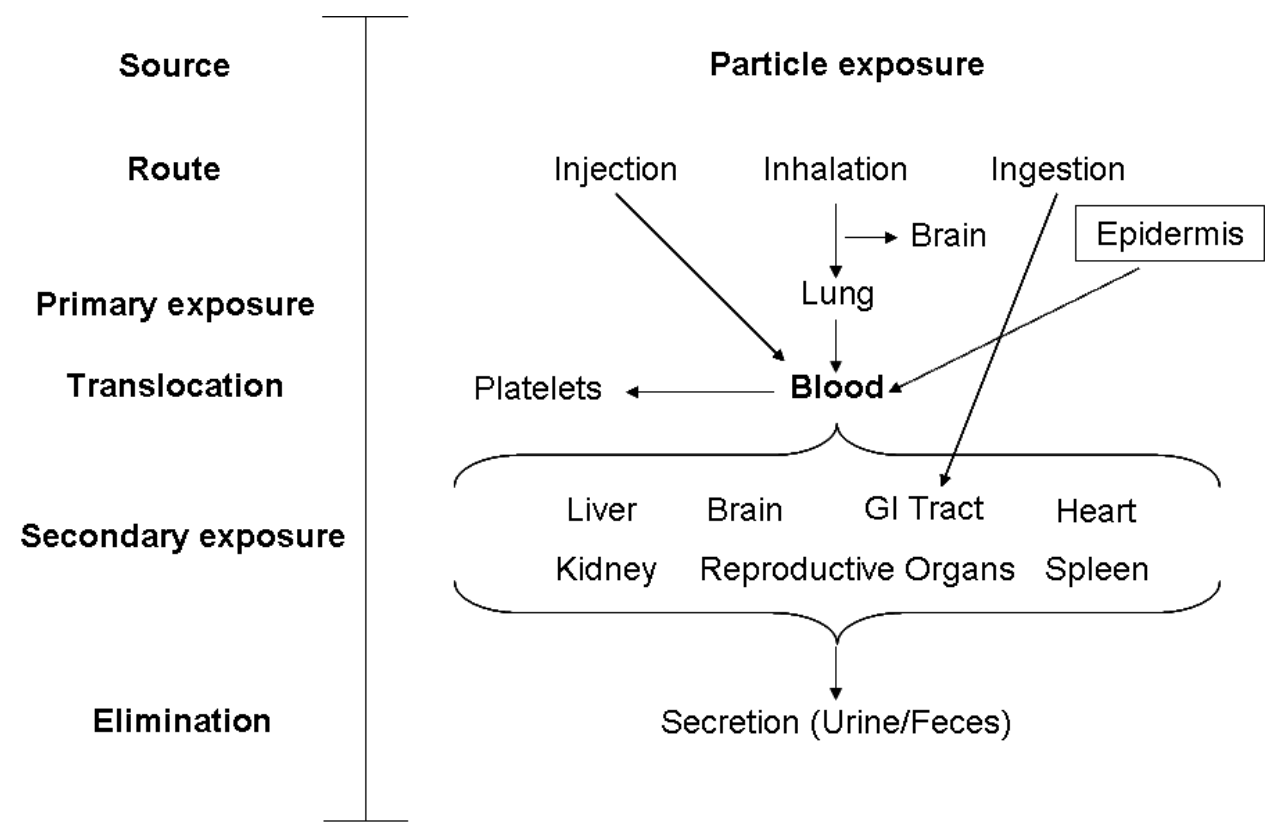

These factors are important to NP toxicology since the realisation that NP localisation and fate is not only restricted to their portal of entry (Fig. 1). Recently, it has been reported that NPs can be distributed to organs distal to their site of exposure, so that potential NP toxicity can occur in any number of secondary targets (i.e. liver/ kidney/brain) (8). Research into the possible secondary toxicity of NPs (i.e. in distal organs from their original exposure route) is extremely limited and is very much in its infancy. Despite this, the limited number of studies investigating the effects of NP translocation to secondary organs have shown that NPs can elicit negative effects to the liver, brain, GI tract (following inhalation), spleen, reproductive systems and the placenta $(20,21,22,23)$.

Although it is essential that the concerns regarding NP translocation and secondary toxicity are investigated, it is imperative that the knowledge gaps associated with the primary exposure organs (lung/gut/skin/blood) are studied. Currently, research into the effects of nanomaterial exposure via ingestion is negligible. The understanding of the 
effects of NPs following injection is also limited. Analysis of the effects of nanomaterials on the skin however, although also being in its infancy, has widely suggested that the optimal opportunity for uptake by the epidermis is when the outer skin cells are broken, such as when the skin is sunburned or diseased (24). Tinkle et al. (25) hypothesised that when broken skin is flexed it is more sensitive to penetration by NPs, such as titanium dioxide $\left(\mathrm{TiO}_{2}\right)$, as it forms a more permeable environment, allowing translocation of the nanomaterials to the lymph nodes and then subsequently into the blood circulation. In addition there is ongoing discussion at the moment if certain NPs can penetrate the epidermis by hair follicles and/or sweat glands (24). Further investigation is necessary in order to support this hypothesis, as well as to fully understand the interaction of NPs with both healthy and diseased/injured skin.

Although information relevant to the interaction of NPs with the gut, blood and skin are relatively unknown, the interaction of NPs with the lung has been well documented over the past twenty years $(7,26,27)$, and is the focus of the present review.

Indeed, exposure to most forms of NPs will initially be via inhalation, especially when considering occupational exposure, and thus will affect the respiratory system (7). The exposure of NPs to biological systems of the lung, specifically cell (mono)cultures, has been a basis for increased discussion recently $(28,29)$. In most nanotoxicology studies, particles are applied in suspension (for example, suspended in cell culture medium). If NPs are to translocate from the lung to secondary target organs (such as the liver or brain) then it is possible that the interaction between NPs and cells could be relevantly mimicked via NP suspension exposure to cell cultures (due to the NPs being translocated within blood). This aspect however, as previously highlighted, requires further, in-depth analysis to (i) determine if and how NPs are translocated from the lung and (ii) at what dose/concentration the NPs are translocated in and thus interact with the secondary organs. In addition, it is paramount that the specific characteristics of the translocated NPs are determined, as it is also possible that they are no longer in the same format as the NPs that entered the lung. Therefore, in order to achieve a more advantageous correlation between the in vitro and the in vivo situation, regarding specific NP-lung interactions, cells should be cultivated at an air-liquid interface and the particles have to be applied from the air. In order to study particle-cell interactions in cell culture systems representing the airway epithelial barrier, it is important to mimic the in vivo interactions of particles with cells as closely as possible. The particles have to maintain their shape as well as their chemical and physical properties when they come into contact with the cell surface to realistically clarify which particle properties contribute to toxic effects. As highlighted previously, the majority of existing cell culture models used to assess lung cell-particle interactions use cells immersed in medium, with particles added to the cell cultures as a suspension in liquid $(30,31,32,26,33)$. This does not however, reflect the 
physiological condition of lung epithelial cells, which are exposed to air, and separated from it by only a thin liquid lining layer with a surfactant film at the air-liquid interface $(32,35,36)$. In order to rectify this issue, a number of exposure systems have been constructed to enable the assessment of various different NP types on lung cell cultures at the air-liquid interface $(28,37-39)$.

The following four sections of this review will describe, in detail, as well as summarise the current research activities of four different exposure systems. It is pertinent to highlight that each exposure system has been established for and used with in vitro cell systems, specifically, unless otherwise stated, the 3D triple cell co-culture model of the epithelial airway barrier as described originally by Rothen-Rutishauser et al. (40) and subsequently in respect to air-liquid interface exposure by Blank et al. (41, 42). Although concentrated upon these cell-types and in vitro model, the advantages of all systems presented below is that they are able to use both in vitro and ex-vivo cell types, as well as tissue samples.

\subsection{An Exposure System to Study the Effects of Occupational Exposure to NPs}

As highlighted previously, the advent of nanotechnology has created an almost exponentially growing market for nanosized materials, which are currently crossing the border from purely industrial commodities to key ingredients for consumer products (43, 44). In this context therefore, identification and understanding of the potential hazards related to such NPs is imperative from a human health viewpoint, and specifically an occupational safety perspective. Since the lung, as already discussed earlier in this review, is considered as the main portal of entry for NPs into the body, a high risk (hazard $\mathrm{x}$ exposure) potential can be attributed to aerosols (45).

Due to the broad applicability and low cost associated with aerosol technology, it is an attractive approach for the manufacture of a wide variety of (nano)materials (46). The production of aersolised NPs however, gives rise to a potentially high level of inhalation exposure. When NPs are produced via gas phase processes, primary particles are formed and can be potentially released into the workplace atmosphere during the initial synthesis stage and subsequently particulate agglomerates can be released during powder recovery as well as in any further processing or packaging (45). In relation to the concerns of the potential for NPs to adversely affect human health, the effects of this process therefore, have a potentially high risk level and demand investigation.

Due to the obvious difficulties in studying the effects from this form of NP production in workers within an occupational setting, it was imperative that such a scenario could be realistically reproduced in order to fully understand the potential for NPs to cause adverse 
effects, particularly in the lung (exposure of NPs to the skin is also a concern in an occupational setting, although this is dependent upon the specific health and safety precautions taken). Therefore, an exposure system was recently established to mimic the exposure of NPs in an occupational setting (Fig. 2) (28). This in vitro exposure system allows the direct exposure of lung cells to airborne NPs, generated in situ by an industrial gas-phase process, therefore avoiding any modification of the aerosol during transition from the particle source to the exposure site (28).

A detailed description of this exposure system has already been published (28). Briefly, the exposure system is installed in a gas tight glove-box apparatus, with a volume of approximately $2.5 \mathrm{~m}^{3}$. The NP aerosol is produced by a pilot scale flame spray synthesis reactor. In principle, a combustible precursor-solvent mixture is fed through a capillary into a methane-oxygen supporting flame. Liquid leaving the capillary is dispersed in oxygen, resulting in a burning spray of about $10 \mathrm{~cm}$ in height. Flame spray synthesis is a highly controllable and well understood process and allows the production compartment of particles composed of almost any metal oxide (such as cerium dioxide $\left(\mathrm{CeO}_{2}\right), \mathrm{TiO}_{2}$ and zinc oxide $\left.(\mathrm{ZnO})\right)$ or salts. Furthermore, the synthesised particles appear in a defined, pure, dry state, which avoids co-deposition of the dispersant (e.g. $\mathrm{H}_{2} \mathrm{O}$ ), and which is immediately apparent upon nebulising the particle suspension(s). The cell cultures are located $\sim 1 \mathrm{~m}$ from the flame reactor, thus avoiding any form of thermal effects. The reactor off gases (which contain NPs) are distributed homogenously in the glove box via a constantly running ventilator placed $0.2 \mathrm{~m}$ from the flame. This active mixing is essential since the characteristic diffusion length of the particles is not sufficient to disperse them uniformly in the glove box by means of diffusion. Finally, in order to maintain ideal cell culture conditions within the glove-box, the cultured cells (currently the system is only established with 6-well plates, however by performing specific control experiments, it would be possible to use 12- or 24- well plates) are placed on a heating plate set at $37^{\circ} \mathrm{C}$, whilst the humidity of the glove-box atmosphere is maintained at $70-80 \%$ by using a waterbath. Temperature and humidity are measured in real time and the aerosol can be characterised (e.g. particle number and size distribution) online by equipping the box with the appropriate measuring devices (such as a scanning mobility particle sizer (SMPS) or miniDiSC). In addition, further off-line analysis can be performed by collecting particles on a filter. The filter can be placed above the flame for characterisation of a wide variety of parameters (e.g. specific surface area, chemical composition (purity) and size analysis of the resulting collected nanopowder).

Recent studies performed using this exposure system have shown that altered cellular responses can be associated with the intracellular accumulation of $\mathrm{CeO}_{2} \mathrm{NPs}$ in lung cells in vitro over time $(28,47) . \mathrm{CeO}_{2}$ was specifically chosen as it is a representative industrial particle, due to its wide use as pigment and polishing agents, as well as a fuel 
catalyst $(48,49)$. Additionally, recent studies have reported that cerium-containing particles were found in the lungs of workers who were exposed to $\mathrm{CeO}_{2}$ aerosols at their workplaces $(50,51,52,53,54)$. Therefore, the need to understand the effects of occupational exposure to this material is essential.

In summary, a novel approach to directly expose air-liquid cultivated lung cells in vitro to airborne NPs, mimicking occupational exposure parameters has been established. This experimental setup enables the effects of occupational exposure to NPs to be investigated thoroughly and subsequently provide essential information for future NP production. In addition, this exposure system is well controlled as it avoids any modification of the aerosol during transition from the particle source to the exposure site and allows dose-controlled deposition of particles to a variety of different in vitro cell systems.

Figure 2. Schematic drawing of the glove-box exposure system. The red arrow illustrates the initial flame-synthesis production of the NPs culminating in the exposure to lung cells in vitro. Adapted from Rothen-Rutishauser et al. (28).

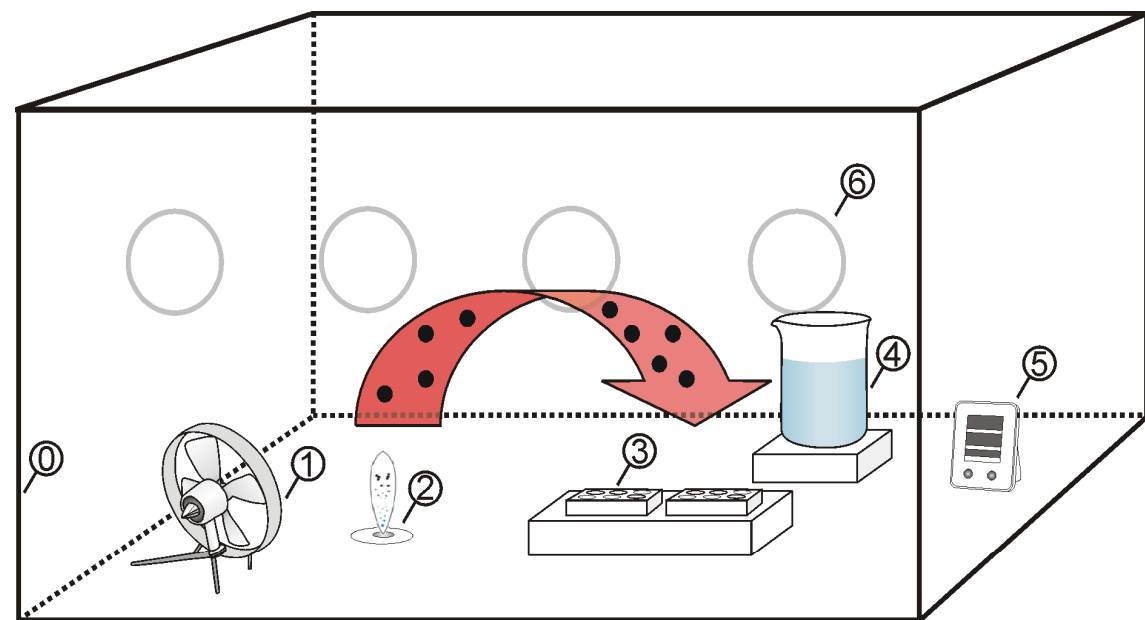

(0) Glove-box $(2.5 \times 1.0 \times 0.9 \mathrm{~m})$

(4) Humidifier

(1) Fan / Ventilator

(5) Thermo-/hygrometer

(2) Flame Spray Synthesis of NP

(6) Holes for gloves

(3) Cultures on heating plate 


\subsection{An Exposure System to Study the Effects of NPs for use in Nanomedicine}

Although it is imperative that the potential occupational exposure of NPs, and the subsequent effects to workers is assessed, investigation into the possibility that NPs are inhaled during their application is also of extreme importance. The interest in NPs for pharmaceutical as well as therapeutic and diagnostic applications (i.e. the field of nanomedicine) has increased rapidly during the last decade (55). Different NP types with specific features for drug delivery (56), imaging (57) or therapeutics (58) have been designed and manufactured. Administration of such NPs is intended to be via inhalation, injection and ingestion (56). To determine the potential adverse effects and possible translocation from the primary site of entry of these NPs, different approaches are required to mimic the in vivo situation. As highlighted previously, in vitro application of the NPs in suspension, i.e. under submerged cell cell culture conditions, would simulate the exposure situation in the bloodstream (following injection exposure), but not in the airways. In order to study the interaction of proposed medical NPs with the lung,under in vitro conditions, an air-liquid interface cell exposure (ALICE) system has recently been established (37) for liquid substances including NP suspensions.

The ALICE system (Fig. 3) has previously been described in detail by Lenz et al. (37). It consists of four main components; i) a 'droplet generator' (nebuliser), that generates a dense cloud of droplets, ii) an 'exposure chamber', where the cell exposure occurs, iii) an 'airflow flow system with an incubation chamber', which provides temperature and humidity conditions suitable for cell cultivation and iv) a 'quartz crystal microbalance' (QCM) for real-time measurement of the cell-delivered NP dose. During an exposure experiment a dense cloud of micron-sized droplets (mass median diameter 4.4-5.4 $\mu \mathrm{m}$ ) containing the NPs is generated by a vibrating membrane droplet generator (investigational eFlow, PARI Pharma GmbH, Munich, Germany). Vibrating membrane nebulisers exert less shear forces and produce less heat than the more widely used jet nebulisers or ultrasonic generators, which is essential to maintain the biological integrity of delicate therapeutic agents, such as biopharmaceuticals (59). The dense cloud of droplets generated by the eFlow nebulizer is transported at a flow rate of 51/min into the exposure chamber $(20 \times 20 \times 30 \mathrm{~cm})$ where it gently deposits (due to gravity) onto the cells cultured at the air-liquid interface in standard cell culture plates. Droplet deposition occurs due to single particle sedimentation and an effect known as cloud settling (i.e. the cloud of droplets moves like a bulk object rather than a collection of individual droplets) (37). The flow rate is specifically chosen to obtain the most uniform spatial distribution of the cloud in the exposure chamber resulting in uniform droplet deposition on the cells. The entire exposure takes about 10 to 15 minutes. Optimal cell culture conditions during the exposure are maintained by placing the exposure chamber and the nebuliser in a 
thermostated incubation chamber $\left(37^{\circ} \mathrm{C}\right)$ and by humidifying the airflow of the exposure system to $80-95 \%$ relative humidity by bubbling the air through a water reservoir (ca. $37^{\circ} \mathrm{C}$ ) (Fig. 3). A filter and a cold trap remove droplets and excess water vapor, respectively from the closed-loop airflow exiting the exposure chamber, in order to protect the air pump.

The ALICE is characterised by high spatial uniformity of the droplet deposition pattern $(<2 \%$ variability) across the bottom plate of the exposure chamber, where the cells are located, and by a high droplet deposition efficiency of $57 \%$ on the bottom of the plate in the exposure chamber. Due to limited cell coverage of the bottom plate, this corresponds to a cell delivery efficiency of about $7 \%$ for standard 6 -well plates, i.e. $7 \%$ of the NP suspension in the reservoir of the eFlow nebulizer reaches the cells. The exact (mass) dose delivered to the cells can be monitored with a quartz crystal microbalance (QCM, Model 200/25, Stanford Research Systems, Sunnyvale, CA, USA) (60), which is placed on the bottom plate of the exposure chamber. Since QCMs are also sensitive to viscoelastic effects, the liquid film deposited on the QCM has to be dried by an air blower after the ALICE exposure has been completed. Surface-specific masses even below $18 \mathrm{ng} / \mathrm{cm}^{2}$ can be detected. This corresponds to about 0.03 monolayer of (e.g.) gold NPs $\left(\right.$ density $\left.=19 \mathrm{~g} / \mathrm{cm}^{3}\right)$.

Figure 3. Schematic drawing of the ALICE system. A nebulizer generates a dense cloud of NP-containing droplets, which is transported into the exposure chamber where the droplets in a spatially uniform manner deposit spatially uniform onto the pulmonary cells cultured at the air-liquid interface. Optimum cell culture conditions are maintained by an isolation box (or incubation chamber) and a closed-loop air flow system with a humidifier. Accurate measurement of the cell delivered mass dose is obtained with a quartz crystal microbalance. Adapted from Lenz et al. (37).

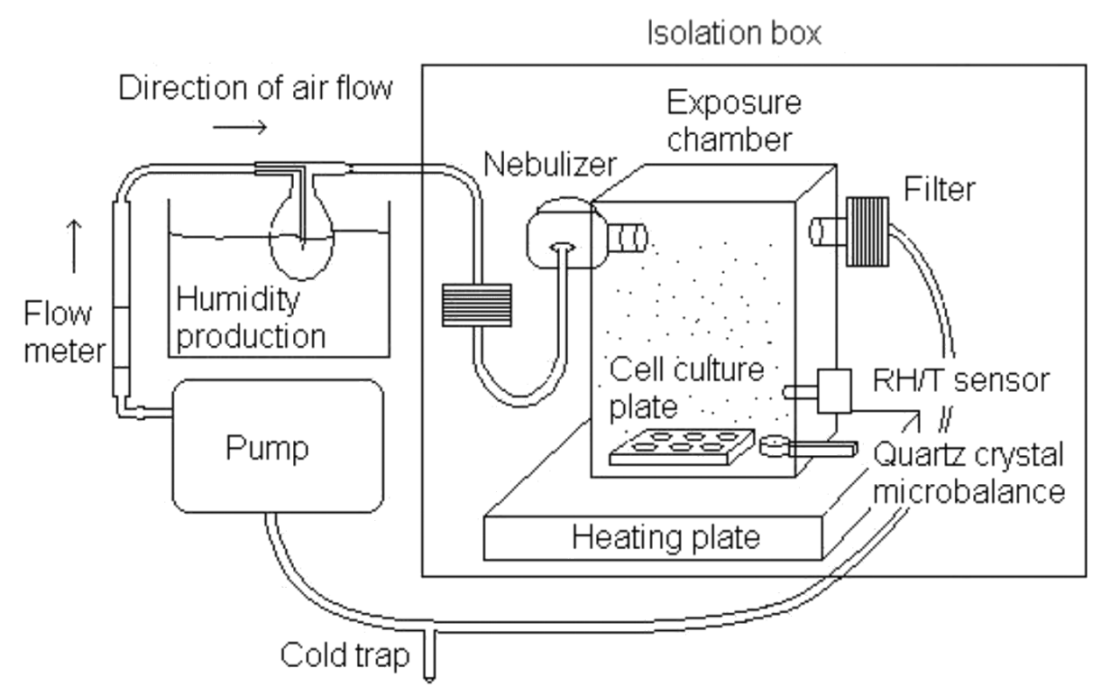


Gold NPs show promising features for biomedical applications in imaging, drug delivery or biosensing due to their inert characteristics and the ability to coat them with any biomolecules (61). Due to this, the ALICE system has recently been used to study the effects of gold NPs on lung cells in vitro. The effects and uptake of $15 \mathrm{~nm}$ gold NPs (62) has been studied in the 3D in vitro alveolar epithelial triple cell co-culture model (40). Besides effects and uptake, intracellular trafficking of gold NPs has been reported, with a coating dependent uptake and intracellular transport (63). The coating, polyethylene glycol (PEG), an agent commonly used to coat NPs intended for biopharmaceutical applications to enhance biocompatibility (64), was found to lead to reduced cellular NP uptake and to cause differences in cellular entry mechanisms compared to uncoated gold NPs. Gold NPs at a size range of $15 \mathrm{~nm}$ however were not found to cause significant oxidative stress or inflammatory reactions at a deposition concentration of 561ng gold $/ \mathrm{cm}^{2}$ after 4 hours and 24 hours compared to baseline levels (62).

In addition to these studies, a comparative study investigating the difference in toxicological cellular response after exposure to 0.3 to $8.5 \mu \mathrm{g} / \mathrm{cm}^{2} \mathrm{ZnO}$ NPs in the ALICE system and the submerged (or suspension) exposure method was performed. The type-II epithelial-like A549 cell-line was exposed to 0.3 to $8.5 \mu \mathrm{g} / \mathrm{cm}^{2} \mathrm{ZnO}$ NPs. After an incubation time of 3 hours the cellular effects, specifically oxidative stress and inflammatory response, following each exposure method were analysed in A549 cells, a type-II human epithelial-like cell-line from the lung (37). Interestingly, it was observed that exposure using the ALICE system elicits a significant different cellular response than to submerged exposed cultures. Cells exposed in the ALICE system were found to show increased levels of oxidative stress at exposure concentrations $>0.3 \mu \mathrm{g} / \mathrm{cm}^{2}$, as determined by heme-oxogenase-1 expression (HO-1), when compared to submerged exposures. Additionally, mitigated pro-inflammatory interleukin (IL)-8 expression was measured after cell exposures in the ALICE for $>2 \mu \mathrm{g} / \mathrm{cm}^{2}$. Differences in cellular uptake were also analysed in both systems by quantifying the amount of gold NPs entering the cells by means of stereology (63). It was observed that a significantly decreased number of NPs were able to interact with the epithelial cells following exposure via the submerged method. This could possibly be due to diffusional NP losses which occur when using the suspension method (32), and which do not occur under air-liquid interface exposure conditions in the ALICE (62). Additionally, an increased agglomeration of plain (uncoated) gold NPs was observed after submerged exposure, which was also attributed. to impacting upon the cellular uptake mechanisms and subsequent effects. These findings are extremely important in relation to understanding and investigating the potential toxicity of NPs, since they clearly show that the effects observed are strongly dependent on particle density and size which determine NP sedimentation or diffusion, and therefore 
highlighting the need for realistic exposure methods when studying the effects of NPs in vitro.

Finally, it is important to note that when establishing the ALICE system, potential side-effects resulting from its use (i.e. non-NP related effects) have been examined by analysing cell viability (WST-1 test) after exposure in the ALICE as well as under submerged conditions to control substances (i.e. $10 \mathrm{mM}$ aqueous $\mathrm{NaCl}\left(0.9 \mu \mathrm{g} / \mathrm{cm}^{2} \mathrm{NaCl}\right)$ and $10 \mathrm{mM}$ tri-sodium citrate dihydrate solution $\left(4.4 \mu \mathrm{g} / \mathrm{cm}^{2}\right.$ citrate) $)(37)$. Although the viability of the cells was initially reduced ( $87 \pm 2 \%$ relative to submerged cells) there was no significant difference between exposed and non-exposed cells detected after exposure. It is therefore very likely that the 18 hours adaptation of the cells to the air-liquid interface prior to exposure was responsible for the observed effect but not the ALICE exposure procedure. It is noteworthy that slight reductions of cell viability after transfer of submerged cells to the air-liquid interface were also reported by other studies $(65,66$, 67) Consequently, neither cell handling in the ALICE nor exposure of the cells to salt solutions impaired cell viability (37).

In summary, the ALICE allows uniform, efficient and dose-controlled deposition of NP suspensions onto cells at the air-liquid interface. The closed system can be operated without any prior knowledge in aerosol technology. Also it is a 'gentle' technique, compared to high-speed spray-deposition, where cellular stress may be induced due to high-speed droplet deposition. Furthermore, the ALICE allows fast, accurate and quasi real-time measurements of the delivered NP (mass) dose to cells using a QCM. Finally, by employing 'slow' gravimetric sedimentation as a deposition mechanism the ALICE system realistically simulates in vivo conditions in the alveolar region and hence, in combination with using the triple-cell culture model, provides a valid alternative to animal-based research. Furthermore, the system is not only applicable to cells but also to other types of biological material such as tissue sections or even micro-organisms making the ALICE a powerful in vitro tool for toxicological studies for a vide variety of substances.

\subsection{An Exposure System to Study the Effects of Exhaust Emissions}

Despite the need for increased research upon the potential human exposure of manufactured NPs, since the concerns attributed to exposure to manufactured NPs are based upon the knowledge and understanding of NPs contained within air pollution, it is essential that they are continually assessed $(4,7)$.

Motorised vehicles can emit air pollution in the form of particulate matter (PM). Although containing matter of all sizes, it has been $\mathrm{PM}$ with a diameter $<10 \mu \mathrm{m}\left(\mathrm{PM}_{10}\right)$ 
which has been widely studied due to its ability to deposit within the upper respiratory tract and subsequently elicit adverse health effects in both health and diseased individuals (68). The composition of exhaust emissions is diverse, containing $\mathrm{PM}_{10}$ as well as numerous gaseous variables including, for example, nitrogen oxides $\left(\mathrm{NO}_{\mathrm{x}}\right)$, carbon monoxide (CO), hydrocarbons and other highly toxic gases. These gases and PM10 are known to elucidate a toxic response towards cells $(69,70,71,72)$ as well as being associated with the development of severe pulmonary and cardiovascular diseases, such as chronic obstructive pulmonary disease $(73,74,75,76,77)$. With an ever-increasing number of motorised vehicles on the road throughout the world, it is imperative that an understanding of the potential for exhaust fumes to contribute to $\mathrm{PM}_{10}$, and subsequently the associated adverse health effects is obtained. In order to identify these aspects and to distinguish the most 'toxic' fractions of exhaust emissions of the many different vehicle types, and since it is extremely difficult to examine such effects in the lung of humans and in vivo, a special exposure system which incorporates in vitro lung cell cultures is imperative.

Constructing a system to study the potential adverse health effects of exhaust emission exposure is extremely challenging. It is essential that such an exposure system for exhaust emissions combines a good exhaust characterisation with a realistic exposure procedure for biological samples. The characterisation of the exhaust emissions has to include the analysis of both gaseous and particulate compounds. In addition, the realistic exposure system has to consider different factors, such as the removal and the dilution of the exhaust emission sample. When performing this, condensing the hot, emitted exhaust emissions (depending on the vehicle and engine type, this can be in the range of several hundred degrees Celsius) has to be avoided. It is essential that this is undertaken, as it is important not to alter the exhaust emission particulate fraction. By using an exhaust emission dilution of at least 1:10 this issue can be resolved. Realistically however, a dilution for the air breathed-in by individuals on the street two-to-three meters away from a driving vehicle would be 1:100 (78). Another factor is the process of particle deposition upon the cell cultures. During respiration, the flow velocity of the air in the lung is slow and gas exchange occurs via a process of diffusion (79). Exposure of the exhaust emissions in relation to cell cultures therefore should also be by diffusion. Upon adding the cell cultures to the exposure system, it is also necessary to control the conditions within the exposure system. Prior to exposure of exhaust emissions the cell cultures require standardised conditions $\left(80 \%\right.$ relative humidity, 5\% carbon dioxide $\left(\mathrm{CO}_{2}\right)$ and $37^{\circ} \mathrm{C}$ ). These conditions are also required during the exposure period, when, depending on the dilution factor, the applied concentration of oxygen $\left(\mathrm{O}_{2}\right)$ should also be controlled.

Such an exposure system has been constructed and has previously been described by Muller et al. (38). Briefly the gas flow of the entire system is driven by a vacuum pump 
(Busch, SV 1010 B) at the end of the system (Figs. 4 and 5). The diluted exhaust emissions are controlled by rotameters (VAF Fluid-Technik GmbH, LVS) at $21 / \mathrm{min}$ and are conducted in a perbunan hose BUNALIT (inner diameter of $4 \mathrm{~mm}$; Angst + Pfister AG, Allschwil, Switzerland). In order to reach the necessary conditions for cell culture analysis, after the exhaust emission dilution, filtered medical $\mathrm{CO}_{2}$ (Carbagas, BernLiebefeld, Switzerland) is added to a final concentration of $5 \pm 0.2 \%$ and the exhaust emissions are humidified to $80 \pm 5 \%$ relative humidity by passing through a heated water bath in selective permeable polypropylene tubes (Accurel PP V8/2 HF, Membrana $\mathrm{GmbH}$, Wuppertal, Germany). The exhaust sample then enters a heated isolation box which is controlled at $37 \pm 0.5^{\circ} \mathrm{C}$ and where the two exposure chambers are located (80). The conditions in the exposure chambers are controlled during the exposure period by monitoring the temperature and relative humidity, as well as the $\mathrm{CO}_{2}$ and $\mathrm{CO}$ concentrations before and after exposure.

Figure 4. Schematic overview of the exhaust emission exposure system. Image adapted from Muller et al. (38).
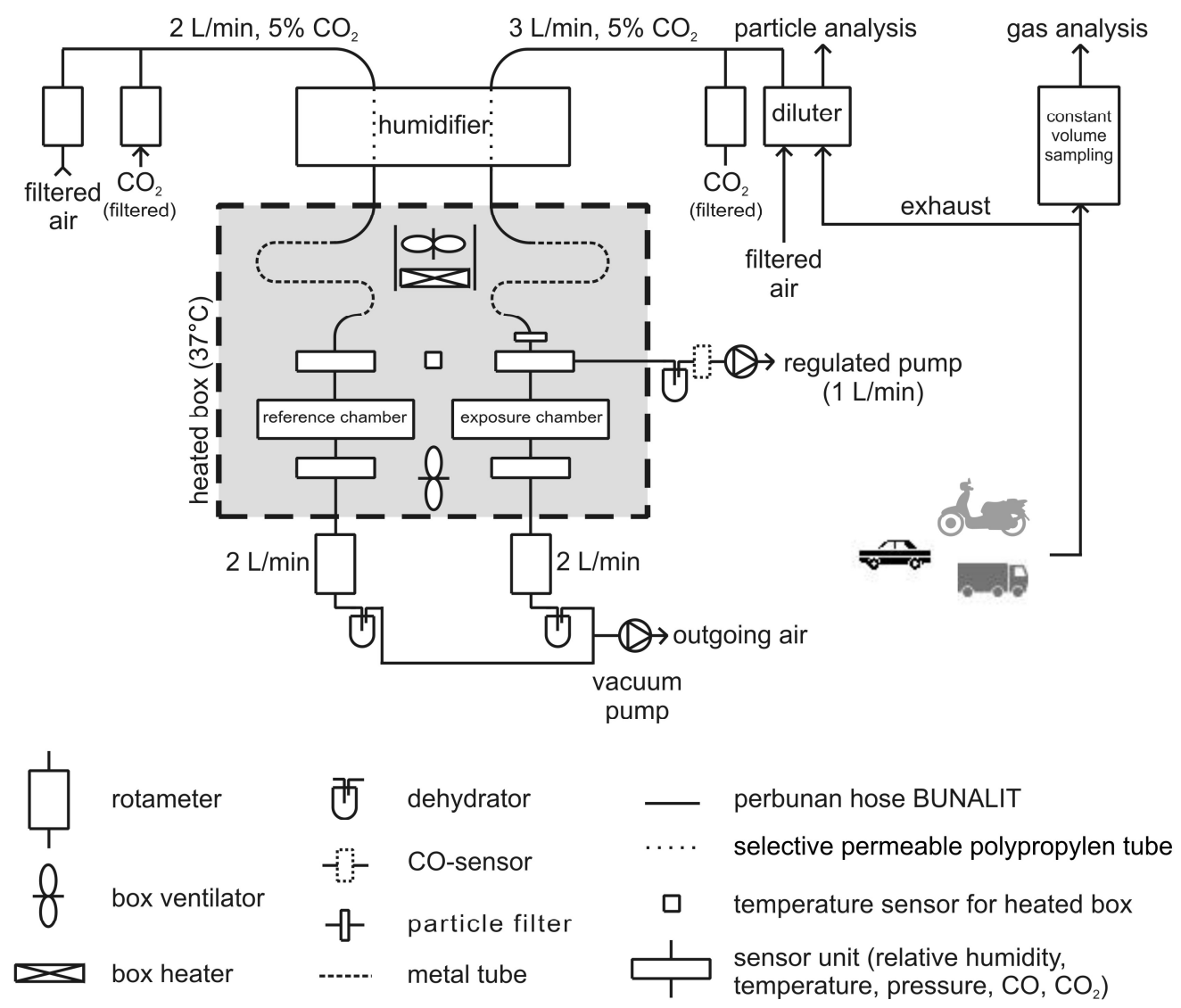
Figure 5. (A) Overview of the exhaust emission exposure system with an example vehicle (scooter) on the chassis dynamometer (1), the rotating disk diluter (2), instrumentation for the characterisation of the particulate compounds (3) and the exposure box (4). (B) The exposure box with the vacuum pump at the end of the system (5) and the heated water chamber for the humidification (6). (C) Exposure (right) and reference (left) chambers for the exposure of cell cultures and the condition control measurement units (7) in the interior of the exposure box. Image adapted from Muller et al. (38).

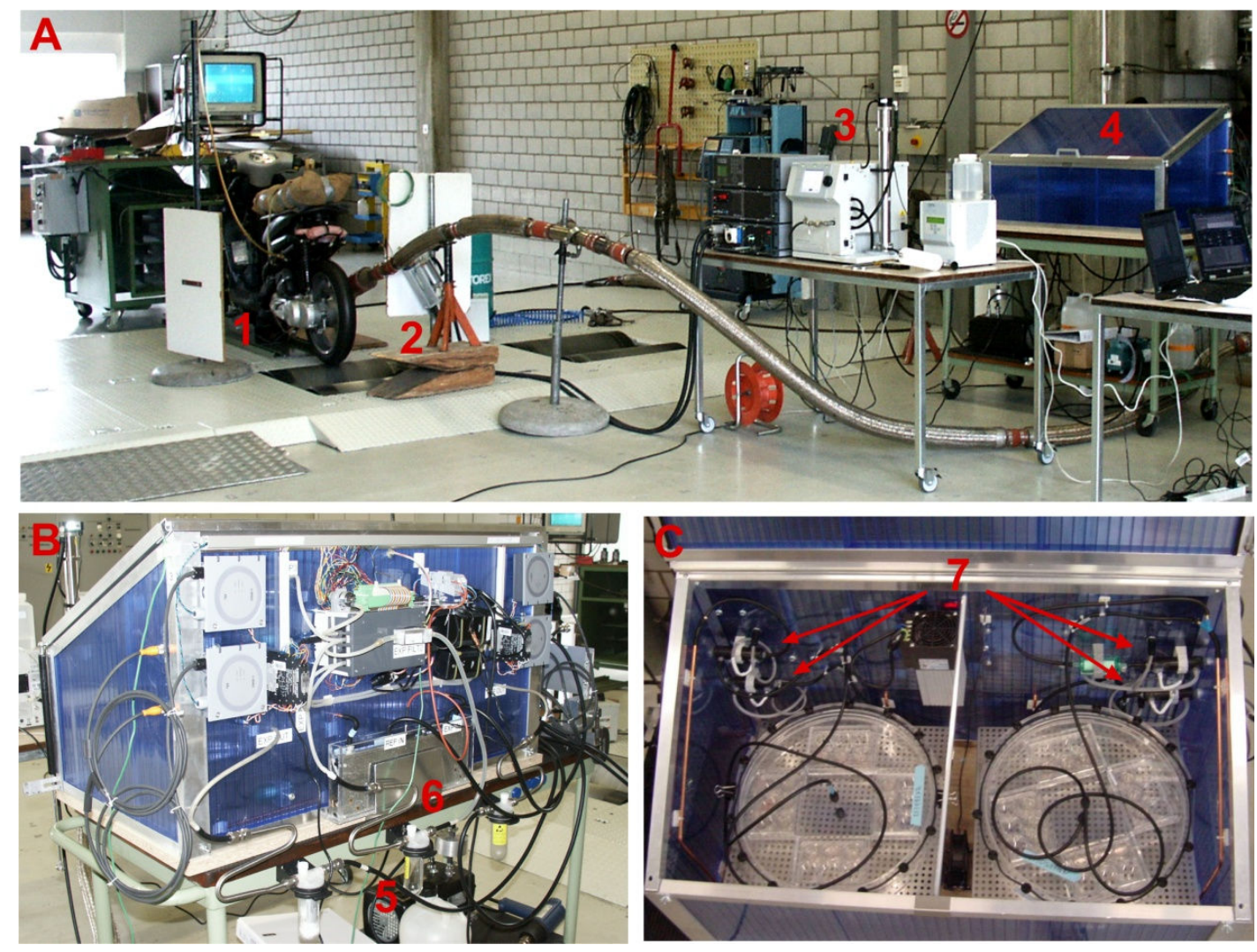

During exposure of cell cultures in vitro, the flow of exhaust emissions is highly defined and follows a special pattern (Fig. 6). In the exposure chamber the diluted exhaust emission sample passes above the cell culture plates and the exhaust emissions diffuse onto the cell cultures. At the bottom of the exposure chamber the exhaust emissions are removed. The pressure difference between before and after the chamber is also measured. Afterwards the humidity is reduced by using dehydrators (Bühler 
Technologies GmbH, distributed by MBE AG, Wetzikon, AGF-PV-30-S2, PVDF/Glas) from the exhaust sample, which is filtered prior to being released into the environment.

Figure 6. Flow pattern in the exposure chamber. Continuous lines show exhaust emissions before the contact with the cell cultures, dotted lines afterwards, twisted arrows symbolise the diffusional contact of the exhaust with the cell cultures. Image adapted from Muller et al. (38).
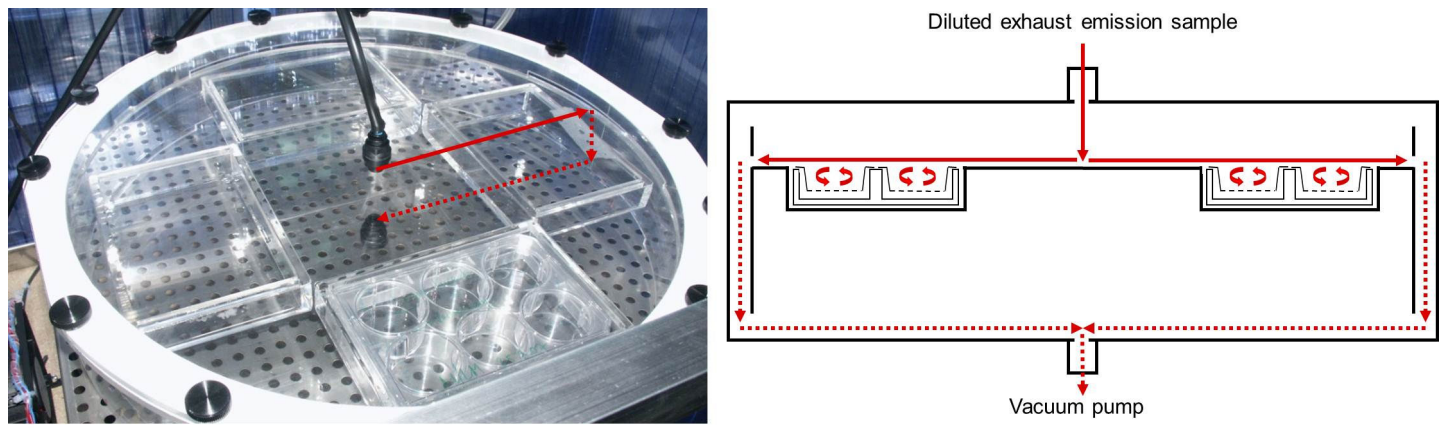

Prior to any cell culture analysis, the system was initially used to characterise scooter exhaust emissions. The exhaust emissions were sampled with constant volume sampling (CVS) following international regulations. Various gas compounds such as hydrocarbons, $\mathrm{NO}_{\mathrm{x}}, \mathrm{CO}, \mathrm{CO}_{2}$ and $\mathrm{O}_{2}$ were measured. The dilution of the exhaust emissions and the characterisation of the particulate compounds were performed using a rotating disc diluter for emissions (Raw Gas Dilution for Aerosols and Gases, Type MD19-2E, Matter Aerosol Engineering AG, Wohlen, Switzerland). The number of particles and the size distribution of particles between 10 and 400nm (using a SMPS consisting of a differential mobility analyser (TSI 3071, model 3081 (long tube)) and a condensation particle counter (TSI 3025 A, model 3772)) as well as the active surface area of the aerosol particles (measured with a diffusion charging particle sensor (Matter Engineering, LQ1-DC)) were determined. When investigating the effects of exhaust emission exposure, a triple cell coculture of the human epithelial airway barrier in vitro (40), was exposed for 2 hours to 1:100 diluted exhaust emissions and post-incubated between 0 and 24 hours. In parallel to the exposure of cell cultures to exhaust emissions, in a second exposure chamber (identified as 'reference' exposures) cell cultures were exposed to filtered ambient air (ultra low penetration air filter; Pall, Pallflex T60A20 Æ $47 \mathrm{~mm}$ ), which was treated and controlled the same way as the exhaust emission, but without the measurement of $\mathrm{CO}$ concentration. In addition, numerous control experiments were also performed. Copper 
transmission electron microscopy grids were placed in the wells of a cell culture plate then evaluated for the number of deposited exhaust particles on the cell cultures following exposure to exhaust emissions (38). Investigation into the toxicity of scooter exhaust emissions is the basis of a number of submitted papers and ongoing projects.

In summary, the exposure system described above and furthermore by Muller et al. (38), provides a model, flexible and realistic exposure system which can be adjusted easily to evaluate the potential for exhaust emissions produced from any vehicle type to cause adverse effects to human health.

\subsection{An Exposure System to Study the Effects of Brake-wear Particles}

Near and on highly congested and busy streets, road traffic can contribute to between $45-65 \%$ of all $\mathrm{PM}_{10}(81,82)$. As previously highlighted, the composition of $\mathrm{PM}_{10}$ is complex and difficult to define, thus it is termed a 'particle cocktail', comprising of a wide variation of particulate materials, including carbon, a complex mixture of metals, exhaust fumes, endotoxins, wind-blown dusts and a mixture of chemicals ranging from $>2.5 \mu \mathrm{m}$ to $<100 \mathrm{~nm}$ in size (83). All of these components are thought to contribute to the observed adverse effects on human health following exposure to traffic $\mathrm{PM}_{10}$ (84). Sources of such components include abrasive wear of tyres, road surfaces and brakes of different types. It has been estimated that brake-wear debris can contribute up to $21 \%$ of total $\mathrm{PM}_{10}$ emissions in Germany (85), a considerable fraction of which is smaller than $100 \mathrm{~nm}$ in size $(86,87)$. The size of these brake-wear particles, as for other nano-sized objects, means that they have the ability to reach the alveoli, the gas exchange units of the lung (88). Due to their ability to deposit in the alveolar region of the human lungs, it has been indicated that brake-wear particles can provoke adverse pulmonary effects (89).

Although previous research has focused upon the in vivo (humans)/epidemiological effects of air-pollution cocktails including brake-wear particles (89), the specific mechanisms associated with such adverse effects have not been able to be studied. Therefore, it has been necessary to develop a system that can measure the direct effects of brake-wear particles, in a realistic manner upon the lung, in vitro.

Here a novel system is presented that was developed to expose in vitro lung cell cultures directly to freshly generated airborne brake-wear particles (Fig. 7). This system has recently been described in detail in Perrenoud et al. (39). Briefly, the main unit of this model system is the 'exposure box' (Fig. 7) which can be mounted around the braking system of many different types of cars.

The exposure box has a volume of $0.2 \mathrm{~m}^{3}$ and contains a humidification (providing 40$50 \%$ humidity (39)) (Fig. 8) and heating unit $\left(37^{\circ} \mathrm{C}\right)$ which can contain any type of cells 
cultured in a 6-, 12- or 24- well plate. The atmosphere of the exposure box is controlled via a HEPA-filtered air and cooling system which provides a clean and stable atmosphere for the cells (Fig. 8).

Prior to cell culture exposure, the vehicle is placed in a 'jacked' position (Fig. 7) and the exposure box is positioned over one free brake (i.e. the wheel is removed from the car). The wheel is removed from the car as to reduce any interference from particles released from the car tyre during the act of braking, as well as to enable direct measurement of brake-wear particles (Fig. 7). The exposure system allows a distance of $1 \mathrm{~m}$ from the cell culture plate to the brake. Cells are placed in the exposure unit 10 minutes prior to exposure and can be accessed via a glove which is installed in one wall of the box. Due to this construction cells can only be exposed to the aerosol during the braking process and apart from that they are covered.

Figure 7. The exposure box (A) with the wide range aerosol sampler (WRAS) (B) for particle counting, the measuring device for polycyclic aromatic hydrocarbons (PAH) quantification (C) and the corresponding data logger (D). Pumps (E) enabled airflow.

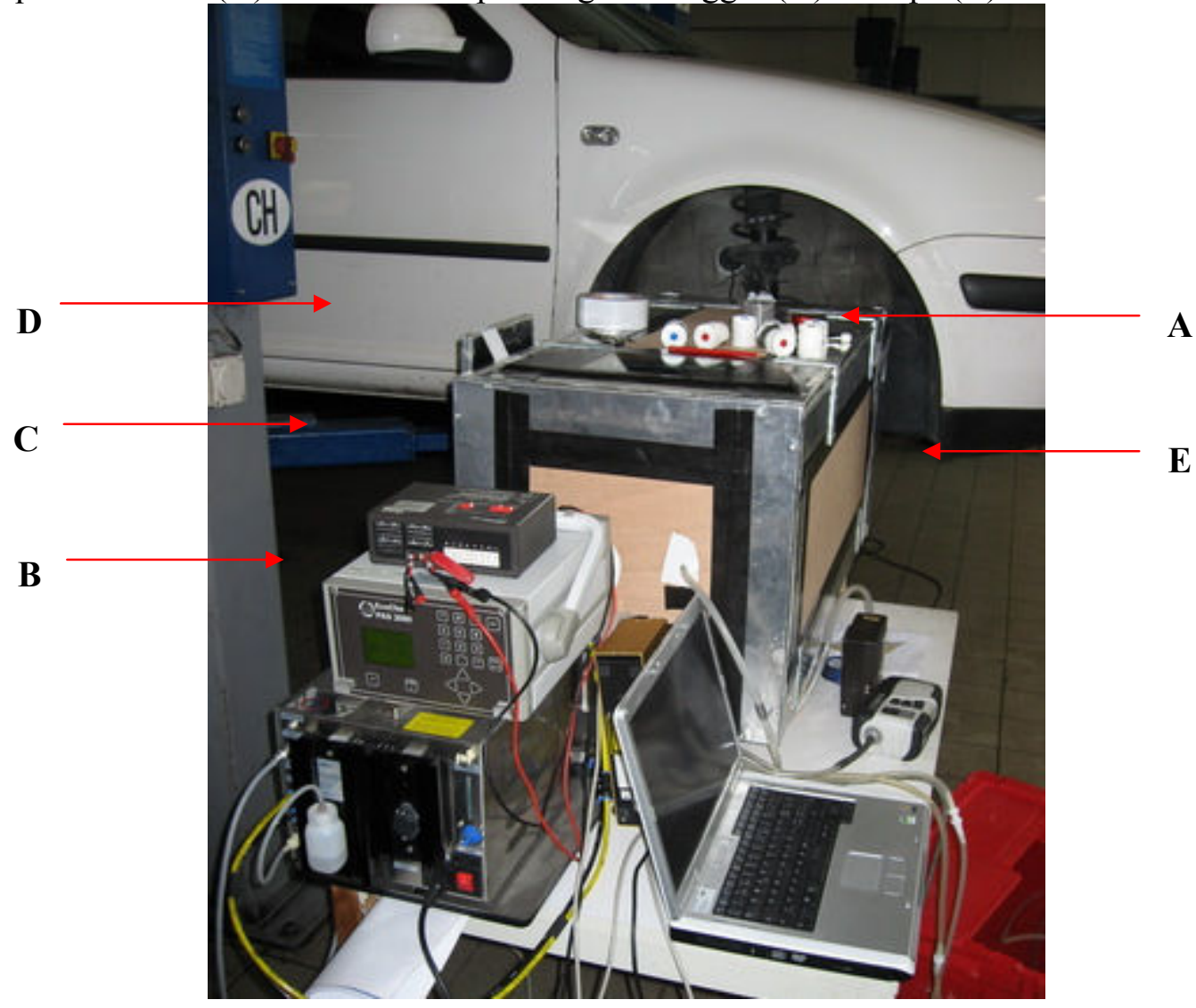


Figure 8. Shows the air supply and the humidification unit including a High efficiency particulate air (HEPA) filter (A). For cooling the internal air of the exposure system, chilled water $(\mathbf{B})$ is pumped through a helix which is located inside the system $(\mathbf{C})$.
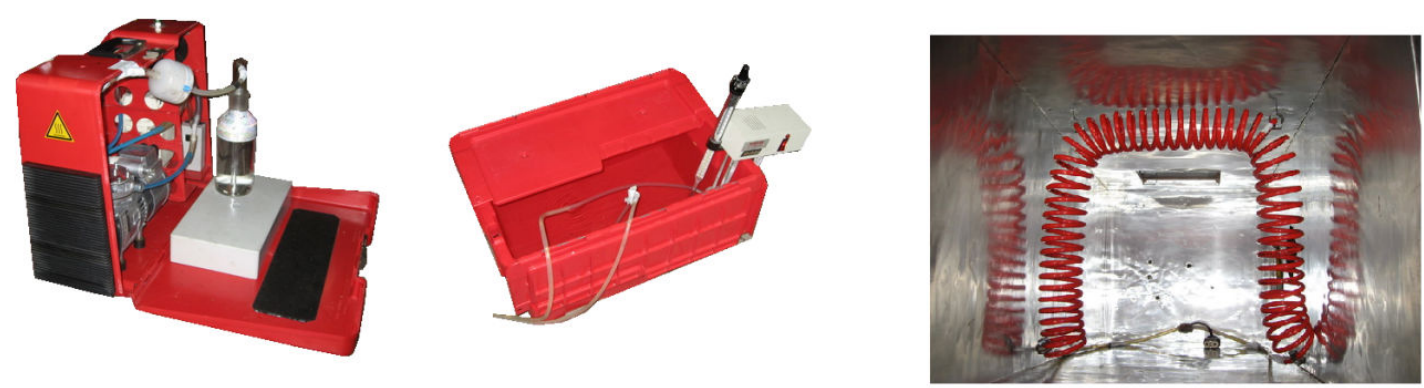

The duration, intensity and velocity of exposure, including the speed of the axle and braking forces are systematically controlled from inside the car. During braking, particles are collected for subsequent analyses and several parameters can be measured online. These include measurement of the particle number, surface and mass distribution in proximity of the cells as performed by a wide range aerosol sampler (WRAS) placed next to the exposure box. Polycyclic aromatic hydrocarbons (PAH) are also measured online by an EcoChem PAS 2000. For carbon analysis, brake-wear particles are collected on quartz filters, which are placed inside the box. After exposure filters are analysed by a coulometric measurement method (90). The PM's metal (iron, copper, manganese) content is determined from PM which is collected on glass micro fibre filters by the OSHA-method ID-121 (91). For visual analyses of the PM and to quantify deposition, coated copper grids for transmission electron microscopy (TEM) are placed inside an empty 6-well cell exposure plate next to the cells during exposure.

To date, experiments performed using this exposure system have used six different car/brake types and three different braking behaviours (92). The three different braking behaviours are defined as; (i) "normal deceleration" - a simulation of typical urban driving behaviour, (ii) "full stop" - a vigorous braking action and (iii) "no stop" - a control rotation of the brake without deceleration (39). It was observed that for all car types the "full stop" had a significantly higher particle number concentration than the "normal deceleration", whereas the "normal deceleration" showed only marginally higher particle number concentration compared to the control "no stop". For all braking behaviours on all car types a significant number of brake-wear particles in the nanometre range $(1-100 \mathrm{~nm})$ was measured. Even though particle size distributions varied between different cars and braking behaviours, a peak at about $100 \mathrm{~nm}$ and another at 300 to $400 \mathrm{~nm}$ were measured from each car type and breaking behaviour. Analyses of the metal compounds released during "full stop" braking showed that iron was measured in the 
highest concentrations (up to $6000 \mu \mathrm{g} / \mathrm{m}^{3}$ ) followed by copper (up to $1000 \mu \mathrm{g} / \mathrm{m}^{3}$ ) and manganese (up to $50 \mu \mathrm{g} / \mathrm{m}^{3}$ ).

Investigation into the adverse effects of brake-wear particles in vitro using this system however, have only evaluated one car/brake type (93). In this study A549 lung epithelial cells were exposed at the air-liquid interface and cellular responses to the brake-wear particles were assessed by measurement of lactate dehydrogenase (LDH). In addition both reactive oxygen species (ROS) and the release of the pro-inflammatory mediator IL8 were also measured since it is known from earlier studies that exposure to $\mathrm{PM}_{10}$ can cause adverse health effects via oxidative stress and inflammatory pathways (84). No significant increase $(p>0.05)$ of extracellular LDH was measured indicating no physical damage to epithelial cell membranes following exposure to brake-wear particles (longest exposure with most particles was for 26 minutes with a total deposition of $1.07 * 107 . \mathrm{cm}^{2}$ for the "full stop" with 8 repetitions) (93). A tendency, although not significant, for ROS levels to increased was observed however, as assessed by fluorescent microscopy and signal quantification. IL-8 stimulation from A549 cells was found to be higher following the "full stop" braking behaviour compared to the negative control and other braking behaviours.

In addition to biochemical analysis, laser scanning microscopy of the tight junction protein occludin revealed structural alterations in brake-wear exposed cells. In control cells occludin was localised at the cell borders and also some staining was seen in the cytoplasm, whereas in cells exposed to the "full stop" braking behaviour the staining at the cell borders was reduced. Signal quantifications of the tight-junction protein occluding further showed a tendency for a decrease after exposure to the "full stop" braking behaviour. Interestingly the decrease of occludin was significantly correlated with an increase of all measured metal (iron, copper and manganese) concentrations. Subsequent statistical analysis showed an additional negative correlation between the amount of occludin and ROS concentration, suggesting that the metal particles produced during the braking process damage tight junctions via an oxidative stress mechanism. It was concluded therefore, by the study by Gasser et al. (93) that brake-wear particles can significantly impair the airway epithelium in vitro.

By the use of this exposure system it was possible for the first time to investigate directly the acute effects of brake-wear particles in vitro. By simultaneously monitoring numerous parameters it was possible to relate the effects to the characteristics of the brake-wear particles. Additionally, by using this system it is possible to expose cell cultures to freshly produced brake-wear particles. As a consequence particles are unable to undergo the same transformation processes (agglomeration, aggregation, reactions with the surrounding fluid) as they would if they were collected and applied via the suspension culture method. Another advantage, specific to the study of Gasser et al. (93) 
is that the A549 epithelial cells used, when cultured at the air-liquid interface, express tight junctions and produce surfactant $(41,94)$, which realistically reflects the physiological conditions of an inhalation exposure. Furthermore, the distance of the cell cultures from the source of the brake-wear particle source enables a particle dilution and therefore creates realistic particle concentrations. Due to this setting and by the support of the cooling system, the heat by the braking process has no direct influence on the cell cultures. Although parameters like the temperature, humidity and background air purity can be kept stable, the system can be quickly adapted to new conditions. Possibilities for future experiments are the use of other cell models such as the triple cell co-culture model of the epithelial airway barrier (40) or the use of alterative car/brake types. With the numerous ports at the rear side of the box, measuring devices can also be adjusted quickly and new parameters can be investigated.

In summary, an exposure system has been established which allows the exposure of lung cells to brake-wear particles whilst simultaneously performing in-depth characterisation of the brake-wear particles emitted from different car types and braking behaviours. By using this model exposure system it has been possible to gain a better understanding of the relationship between the characteristics of brake-wear particles and their subsequent effects and behaviour in biological systems. An initial study has been conducted which presents data highlighting the impairment of the airway epithelium following exposure to brake-wear particles in vitro. In addition, it also indicates the need for further, detailed investigations upon the potential for brake-wear particles to affect the health of the population who live and/or work near to busy and congested roads.

\section{Conclusions}

Over the past twenty years, increased research has shown that NPs can elicit adverse cellular responses, as well as contribute to adverse health effects in both healthy and diseased humans, compared to their larger particle counterparts of the same material and at the same mass dose $(4,7)$. Since NPs are intended to be used in a diverse range of applications, such as cosmetics, sporting equipment and information technology, the routes of exposure to the human body are numerous (19). Due to the ever increasing number and variety of NPs being manufactured for such applications, as well as NPs accidentally released into the environment during their production and use (e.g. release of NPs from aging and abrasion of car tyres), the need to understand and gain knowledge relating to their interaction with the human body is essential (1).

Although the number of published studies that investigate the potential adverse effects related to NP exposure in vitro continues to grow, the specificity and realism attributed to 
such research is limited (18). Examples of which include the lack of realistic concentrations investigated (i.e. that humans will be exposed to), the specific cell cultures used to mimic organs of the human body, as well as how NPs are exposed to these in vitro systems. Although increased research is required to determine the realistic NP concentrations that humans will be exposed to, advances in in vitro systems for nanotoxicology testing have occurred. Recent advances include the in vitro 3D triple cell co-culture of the epithelial airway barrier $(40,94)$, the quadruple co-culture system by (95), containing epithelial, endothelial, macrophage and mast cells which mimic a similar area of the lung, whilst the system published by (96) is a bi-culture of BeWo and human fibroblast cells, which form an in vitro model of the placenta.

In comparison, advances have also taken place in regards to the realistic exposure of NPs in vitro. The present review provides an overview of four available exposure systems that may be used for NP (either manufactured or accidental) inhalation studies in vitro. Each exposure system is novel, providing a valid and advantageous approach compared to the NP suspension exposure method, however is based upon the principle of exposing NPs to in vitro lung cell cultures at the air-liquid interface. In addition to this other aspects are also highlighted by each exposure system which relate to the realistic deposition of NPs and subsequent effects in lung cells in vitro. Namely, investigators can (i) determine the exact dose (concentration) that interacts with the biological system, (ii) expose NPs to biological systems realistically and (iii) be sure that there are no changes to the surface properties of the NPs as well as that the NPs will not unrealistically agglomerate/aggregate during their exposure, which both commonly occur when using the suspension (submerged) exposure method.

It is important to note however, that the exposure systems described and discussed in the present review are not completely novel. There are numerous different exposure systems also available which have been constructed and established to assess the effects of accidental and manufactured NPs. Predominantly, such exposure systems have focussed upon the effects of environmental particulate. A summary of these exposure systems are given in table 1 .

Table 1. Overview of exposure systems related to assessing the effects of environmental particulate and its constituents in vitro and in vivo. Adapted from Muller et al. (38). Definitions for all abbreviations are contained within the list of abbreviations. 


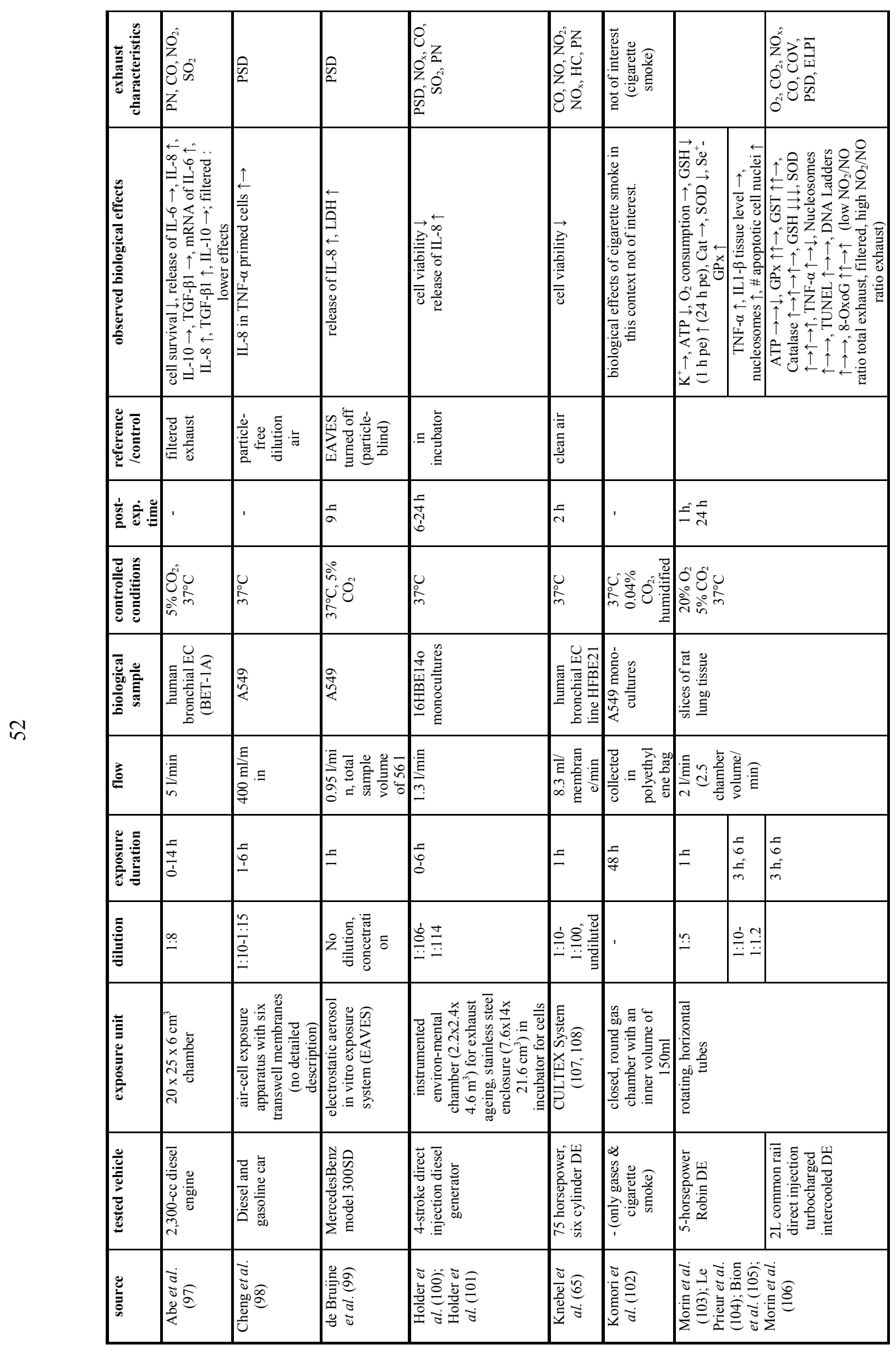


These exposure systems (table 1) all expose the specific biological systems used to freshly produced exhaust emissions, although are limited in some aspects, such as the dilution factor, control conditions (humidity, temperature) and exchange differential implemented.

The ageing of the exhaust emissions, (which is attended by chemical and physical changes of the exhaust emissions), is a fact of the situation on the street and in the natural atmosphere, and therefore should be considered. The exposure system for the exposure of cell cultures to exhaust emissions (38) provides realistic conditions concerning the dilution, the conditions for the cell cultures and the contact of the exhaust emissions with the cell cultures. The dilution of 1:100, as it was used, represents the situation on the road. The exhaust emissions of a driving vehicle are diluted about 1:100 in a distance of two-to-three meters to the vehicle (78). The dilution is not fixed to a ratio of 1:100, but can be adapted to a ratio that is needed. The conditions in the exposure chamber are controlled at $37^{\circ} \mathrm{C}, 80 \%$ relative humidity and $5 \% \mathrm{CO}_{2}$ representing the conditions as they are found in the lung. The contact of the exhaust emissions occurs over diffusion, as it is also the case in the gas exchange parts of the human airways (79). In comparison to other such exposure systems (Table 1) (97-106), as also highlighted in (38), the control of the conditions, the dilution rate and the exchange of diffusion processes are more realistic in the exposure system of Muller et al. (38).

Additional exposure systems also exist in regards to measuring manufactured NPs. One such system, which to a certain extend 'bridges the gap' between environmental particulate exposure systems and those intended to measure manufactured NPs (i.e. 37) is that of Mulhopt et al. (109). This system, highlighted within the EU FP7 project 'Nanosafe' (www.nanopartikle.info), is a portable system which is able to be placed either in a city, the countryside, a workplace or a laboratory to characterise (e.g. aerosol concentration and deposited particulate mass (also using a QCM)) as well as measure the particulate and its constituents on in vitro cultures at the air-liquid interface. Although this exposure system is described as being 'portable', it is a heavy and complex piece of machinery which takes time to set-up and requires a specialised technician to operate it. Nonetheless, in comparison to the exposure systems highlighted in this review $(28,37-39.97-106)$, the exposure system described by Mulhopt et al. (109) is advantageous in assessing the 'real' airborne particulates in the atmosphere (or indoor atmosphere; depending upon its location), rather than assuming specific parameters (e.g. the particle dilution factor) due to its ability to be positioned in numerous measurement locations.

Whilst the use of the system of Mulhopt et al. (109) is, in theory, possible within an occupational and laboratory setting, due to its size it is not desirable and therefore, exposure systems as those highlighted in the present review $(28,37)$ are the closest systems currently possible to mimic occupational exposure to manufactured NPs. In 
addition to this, and in comparison to both the systems described by RothenRutishauser et al. (28) and Lenz et al. (37), based on the previous work of both Bitterle et al. (110) and Tippe et al. (111) is the exposure system described by Savi et al. (112). Similar to the system of Lenz et al. (37), Savi et al. (112) produced an exposure system that enables efficient, reproducible and uniform deposition of NPs (via a nebuliser) onto in vitro cell cultures at the air-liquid interface. In contrast to the ALICE system (37), the exposure system of Savi et al. (112) contains a bipolar Kr-85 charger which causes only some of the particles (that pass through this charger prior to being nebulised over the cell cultures) to carry an electrostatic charge prior to interaction with the in vitro cell cultures; mimicking the mixture of NP charges as would be found in the atmosphere.

As highlighted in this review, there are many different forms of exposure systems that have been established to investigate the interaction of NPs at the air-liquid interface in vitro. Each is slightly different to the next, in regards to the primary aim of the exposure system, however all are based upon the same principle as previously described $(110,111)$. Although all systems are in their infancy and require further adaptations and further research, they provide an advantageous basis over the suspension (submerged) method for understanding the NP-lung interaction. In addition, it is possible, in theory, for each system, as previously highlighted, to be used with in vivo model systems. It is important to note however, that none of the exposure systems highlighted in this review have been used with in vivo systems, and so fundamental baseline, control measurements (such as cell integrity) are necessary prior to any in vivo investigations. If in vivo research were to be performed with these exposure systems, then further adaptations would be required, since there are no exposure units for animals (although it would be straight forward to use ex-vivo systems following control measures). If exposure units were to be constructed and implemented with each exposure system, then the issues of in vivo aerosol research would still be valid (such as the NPs adhering to the fur of the animals and not being fully inhaled by the animals). Such issues would therefore require further research and alteration to the systems. Since however, the exposure systems described in this review were manufactured to compliment the in vitro model of Rothen-Ruthishauser et al. (40) and Blank et al. (41, 42), thus contributing to reducing, refining and replacing animal experimentation, it is not foreseeable that in vivo research would be performed using these systems. Therefore, in conclusion, via the use of such exposure systems concomitantly with advanced in vitro cell culture models as well as off-line biochemical and microscopy analysis (113), it is possible to obtain a clear and defined understanding of the interaction between NPs and the lung as it occurs in vivo. 


\section{Acknowledgements}

The authors would like to thank Barbara Tschirren, Kirsten Clift, Mohammed Ouanella and Andrea Stokes for their vital input to the ongoing research of the laboratory, as well as their assistance for the routine and helpful discussions from which this review has been partially based upon. In addition, the authors would like to thank and highlight the many collaborators with whom the construction and use of the exposure systems described in this review would not have been possible. These include, Prof. Wendelin Stark, Dr. Ludwig Limbach, Dr. Robert Grass (all ETH Zurich, Switzerland), Mr. Pierre Comte (AFHB Biel-Bienne, Switzerland), Prof. Jan Czerwinski (AFHB Biel-Bienne, Switzerland), Dr. Andreas C.R. Mayer (TTM, Switzerland), Dr. Markus Kasper (Matter Aerosol AG, Switzerland), Prof. Jean-Paul Morin (INSERM, Université de Rouen, France), PD. Dr. Michael Riediker (IST Lausanne, Switzerland) and Mr. Alain Perrenoud (Municipality of Langenthal, Langenthal, Switzerland).

The authors would also like to acknowledge the support of the European Respiratory Society, Fellowshop LTRF-MC1572-2010 to Dr. MJD CLIFT, as well as the Swiss National Science Foundation (\#3100A0_118420), the German Research Foundation (DFG SPP 1313), the Animal Free Research Foundation and the Doerenkamp-Zbinden Foundation for their financial support.

\section{List of abbreviations}

3D:

8 OxoG:

ALICE system:

ATP:

Cat:

$\mathrm{CeO}_{2}$ :

$\mathrm{CO}$ :

$\mathrm{CO}_{2}$ :

CVS:

DE:

EC:

ELPI:

GI tract:

GPx:
3 Dimensional

8-Oxo-2'-deoxyguanosine (8 OxoG),

Air-liquid interface cell exposure system

Adenosine-5'-triphosphate

Catalase

Cerium dioxide

Carbon monoxide

Carbon dioxide

Constant volume sampling

Diesel engine(

Epithelial cells

Electrical low pressure impactor

Gastrointestinal tract

Glutathione peroxidase 
GSH: $\quad$ Reduced glutathione

GST: Glutathione S-transferase

HC: $\quad$ Hydrocarbons

HEPA: $\quad$ High efficiency particulate air

HO-1: $\quad$ Heme-oxogenase-1

IL: $\quad$ Interleukin

LDH: $\quad$ Lactate dehydrogenase

$\mathrm{NaCl}: \quad$ Saline

NO: $\quad$ Nitrogen monoxide

$\mathrm{NO}_{2}$ : $\quad$ Nitrogen dioxide

$\mathrm{NO}_{\mathrm{x}}$ : $\quad$ Nitrogen oxides

NPs: $\quad$ Nanoparticles

$\mathrm{O}_{2}$ : Oxygen

PAH: Polycyclic aromatic hydrocarbons

PD: $\quad$ Particle distribution

pe: $\quad$ Post-exposure

PEG: $\quad$ Polyethylene glycol

PM: $\quad$ Particulate matter

$\mathrm{PM}_{10}$ : Particulate matter $<10 \mu \mathrm{m}$

PN: $\quad$ Particle number

PSD: $\quad$ Particle size distribution

QCM: Quartz crystal microbalance

RH/T: $\quad$ Temperature and humidity regulator

ROS: $\quad$ Reactive oxygen species

SCHENIR: $\quad$ Scientific Committee on Emerging and Newly Identified Health

Risks

SMPS: $\quad$ Scanning mobility particle sizer

$\mathrm{SO}_{2}: \quad$ Sulfur dioxide

SOD: $\quad$ Superoxide dismutase

TEM: $\quad$ Transmission electron microscopy

$\mathrm{TiO}_{2}$ : Titanium dioxide

TNF- $\alpha$ : Tumour necrosis factor-alpha

TSI: $\quad$ Two-stroke injection

TUNEL: $\quad$ Terminal deoxynucleotidyl transferase dUTP nick end labeling 
WRAS:

Wide range aerosol sampler

WST-1:

Reagent used in specrophotometric assessment of cell

proliferation

\section{References}

1. Maynard, A.D. Nanotechnology: The next big thing, or much ado about nothing? The Annals of Occupational Hygiene 2007, 51, 1-12.

2. Donaldson, K.; Stone, V.; Tran, C.L.; Kreyling, W; Borm, P.J.A. Nanotoxicology. Occupational and Environmental Medicine 2004, 61, 727-728.

3. Nel, A.; Xia, T.; Madler, L.; Li, N. Toxic Potential of Materials at the Nanolevel. Science 2006, 311, 622-627.

4. Oberdorster, G.; Stone, V.; Donaldson, K. Toxicology of nanoparticles: A historical perspective. Nanotoxicology 2007, 1, 2-25.

5. Royal Society and Royal Academy of Engineers Report. Nanoscience and Nanotechnologies: Opportunites and Uncertainties 2004.

6. Sauer, U.G. Animal and Non-Animal Experiments in Nanotechnology - the Results of a Critical Literature Survey Alternatives to Animal Testing 2009, 26, 109-137.

7. Oberdorster, G.; Oberdorster, E.; Oberdorster, J. Nanotoxicology: An emerging discipline evolving from studies of ultrafine particles. Environmental Health Perspectives 2005a, 113, 823-839.

8. Oberdorster, G.; Maynard, A.; Donaldson, K.; Castranova, V.; Fitzpatrick, J.; Ausman, K.; Carter, J.; Karn, B.; Kreyling, W.; Lai, D.; Olin, S.; MonteiroRiviere, N.; Warheit, D.; Yang, H. Principles for characterizing the potential human health effects from exposure to nanomaterials: elements of a screening strategy. Particle and Fibre Toxicology 2005b, 2, 8.

9. Ferin, J.; Oberdorster, G.; Penney, D.P. Pulmonary retention of ultrafine and fine particles in rats. American Journal of Respiratory Cell and Molecular Biology 1992, 6, 535-542.

10. Oberdorster, G.; Ferin, J.; Morrow, P.E. Volumetric loading of alveolar macrophages (AM): A possible basis for diminished AM-mediated particle clearance. Experimental Lung Research 1992, 18, 87-104.

11. Brown, D.M.; Wilson, M.R.; MacNee, W.; Stone, V.; Donaldson, K. Sizedependent proinflammatory effects of ultrafine polystyrene particles: A role for surface area and oxidative stress in the enhanced activity of ultrafines. Toxciology and Applied Pharmacology 2001, 175, 191-199.

12. Brown, D.M.; Donaldson, K.; Borm, P.J.; Schins, R.P.; Dehnhardt, M.; Gilmour, P.; Jimenez, L.A.; Stone, V. Calcium and ROS-mediated activation of transcription factors and TNF- $\alpha$ cytokine gene expression in macrophages 
exposed to ultrafine particles. American. Journal of Physiology - Lung Cellular and Molecular Physiology 2004, 286, L344-L3535.

13. Scientific Committee on Emerging and Newly Identified Health Risks (SCENIHR). Opinion on; the appropriateness of existing methodologies to assess the potential risks associated with engineered and adventitious products of nanotechnologies. 2005.

14. Scientific Committee on Emerging and Newly Identified Health Risks (SCENIHR). Opinion on; the scientific aspects of the existing and proposed definitions relating to products of nanoscience and nanotechnologies. 2007.

15. Kreyling, W.G.; Semmler-Behnke, M.; Chaudhry, Q. A complementary definition of nanomaterial. Nanotoday 2010, 5, 165 - 168.

16. International Organization for Standardization (ISO) Technical Specification (ISO/TS) 27687:2008. Nanotechnologies - Terminology and definitions for nanoobjects - Nanoparticle, nanofibre and nanoplate. 2008.

17. Maynard, A.D.; Aitken, R.J.; Butz, T.; Colvin, V.; Donaldson, K.; Oberdorster, G.; Philbert, M.A.; Ryan, J.; Seaton, A.; Stone, V. Safe handling of nanotechnology. Nature 2006, 444, 267-269.

18. Oberdorster, G. Safety assessment for nanotechnology and nanomedicine: concepts of nanotoxicology. Journal of Internal Medicine 2010, 267, 89-105.

19. Knol, A.B.; de Hartog, J.J.; Boogaard, H.; Slottje, P.; van der Sluijs, J.P.; Lebret, E.; Cassee, F.R.; Wardekker, J.A.; Ayres, J.G.; Borm, P.J.; Brunekreef, B.; Donaldson, K.; Forastiere, F.; Holgate, S.T.; Kreyling, W.G.; Nemery, B.; Pekkanen, J.; Stone. V.; Wichmann, H-E.; Hoek, G. Expert elicitation on ultrafine particles: likelihood of health effects and causal pathways. Particle and Fibre Toxicology 2009, 6, 19.

20. Kreyling, W.; Semmler, M.; Erbe, F.; Mayer, P.; Takenaka, S.; Schulz, H. Translocation of ultrafine insoluble iridium particles from lung epithelium to extra pulmonary organs is size dependent but very low. Journal of Toxicology and Environmental Health 2002, 65, 1513-1530.

21. Kreyling, W.G.; Semmler-Behnke, M.; Moller, W. Ultrafine particle-lung interactions: does size matter? Journal of Aerosol Medicine 2006, 19, 74-83.

22. Wick, P.; Malek, A.; Manser, P.; Meili, D.; Maeder-Althaus, X.; Diener, L.; Diener, P-A.; Zisch, A.; Krug, H.F.; von Mandach, U. Barrier Capacity of Human Placenta for Nanosized Materials. Environmental Health Perspectives 2010, 118, 432-436.

23. McAuliffe, M. E.; Perry, M. J. Are nanoparticles potential male reproductive toxicants? A literature review. Nanotoxicology 2007, 1, 204-210.

24. Baroli, B. Penetration of nanoparticles and nanomaterials in the skin: Fiction or reality. Journal of Pharmaceutical Sciences 2009, 99, 21-50. 
25. Tinkle, S.S.; Antonini, J.M.; Rich, B.A.; Roberts, J.R.; Salmen, R.; DePree, K.; Adkins, E.J. Skin as a route of exposure and sensitization in chronic Beryllium disease. Environmental Health Perspectives 2003, 111, 1202-1208.

26. Rothen-Rutishauser, B.; Muhlfeld, C.; Blank, F.; Musso, C.; Gehr, P. Translocation of particles and inflammatory responses after exposure to fine particles and nanoparticles in an epithelial airway model. Particle and Fibre Toxicology 2007, 4, 9.

27. Muhlfeld, C.; Rothen-Rutishauser, B.; Blank, F.; Vanhecke, D.; Ochs, M.; Gehr, P. Interactions of nanoparticles with pulmonary structures and cellular responses. American Journal of Physiology - Lung Cellular and Molecular Physiology 2008, 294, L817-L829.

28. Rothen-Rutishauser, B.; Grass, R.N.; Blank, F.; Limbach, L.K.; Mühlfeld, C.; Brandenberger, C.; Raemy, D.O.; Gehr, P.; Stark, W.J. Direct combination of nanoparticle fabrication and exposure to lung cell cultures in a closed setup as a method to simulate accidental nanoparticle exposure of humans, Environmental and Scientific Technology 2009, 43, 2634-2640.

29. Stone, V.; Johnston, H.; Schins, R.P.F. Development of in vitro systems for nanotoxicology: methodological considerations. Critical Reviews in Toxicology 2009, 39, 613-626.

30. Duffin, R.; Tran, L.; Brown, D.; Stone, V.; Donaldson, K. Proinflammogenic effects of low-toxicity and metal nanoparticles in vivo and in vitro: highlighting the role of particle surface area and surface reactivity. Inhalation Toxicology 2007, 19, 849-856.

31. Gurr, J.R.; Wang, A.S.; Chen, C.H.; Jan, K.Y. Ultrafine titanium dioxide particles in the absence of photoactivation can induce oxidative damage to human bronchial epithelial cells. Toxicology. 2005, 213, 66-73.

32. Limbach, L.K.; Li, Y.; Grass, R.N.; Brunner, T.J.; Hintermann, M.A.; Muller, M.; Gunther, D.; Stark, W.J. Oxide nanoparticle uptake in human lung fibroblasts: effects of particle size, agglomeration, and diffusion at low concentrations. Environmental and Scientific Technology 2005, 39, 9370-9376.

33. Stearns, R.C.; Paulauskis, J.D.; Godleski, J.J. Endocytosis of ultrafine particles by A549 Cells. American Journal of Respiratory Cell Molecular Biology 2001, 24, 108-115.

34. Gehr, P.; Schürch, S.; Berthiaume, Y.; Im, H.of V.; Geiser, M. Particle retention in airways by surfactant. Journal of Aerosol Medicine 1990, 3, 27-43.

35. Gil, J.; Weibel, E.R. Extracellular lining of bronchioles after perfusion-fixation of rat lungs for electron microscopy. The Anatomical Record 1971, 169, 185-99.

36. Schürch, S.; Gehr, P.; Im, H.of V.; Geiser, M.; Green, F. Surfactant displaces particles toward the epithelium in airways and alveoli. Respiratory Physiology 1990, 80, 17-32. 
37. Lenz, A.G.; Karg, E.; Lentner, B.; Dittrich, V.; Brandenberger, C.; RothenRutishauser, B.; Schulz, H.; Ferron, G.A.; Schmid, O. A dose-controlled system for air-liquid interface cell exposure and application to zinc oxide nanoparticles. Particle and Fibre Toxciology 2009, 6, 32.

38. Muller, L.; Comte, P.; Czerwinski, J.; Kasper, M.; Mayer, A.C.; Gehr P.; Burtscher, H.; Morin, J-P.; Konstandopoulos, A.; Rothen-Rutishauser, B. New exposure system to evaluate the toxicity of (scooter) exhaust emissions in lung cells in vitro. Environmental and Scientific Technology 2010, 44, 2632-2638.

39. Perrenoud, A.; Gasser, M.; Rothen-Rutishauser, B.; Gehr, P.; Riediker, M. Characterisation of nanoparticles resulting from different braking behaviours. International Journal of Biomedical Nanoscience and Nanotechnology 2010, 1, 1.

40. Rothen-Rutishauser, B.M.; Kiama, S.G.; Gehr, P. A three-dimensional cellular model of the human respiratory tract to study the interaction with particles. American Journal of Respiratory Cell Molecular Biology 2005, 32, 4, 281-289.

41. Blank, F.; Rothen-Rutishauser, B.M.; Schurch, S.; Gehr, P. An optimized in vitro model of the respiratory tract wall to study particle cell interactions. Journal of Aerosol Medicine 2006, 19, 392-405.

42. Blank, F.; Rothen-Rutishauser, B.; Gehr, P. Dendritic cells and macrophages form a transepithelial network against foreign particulate antigens. American Journal of Respiratory Cell Molecular Biology 2007, 36, 669-677.

43. Grass, R.N.; Limbach, L.K.; Stark, W.J. Manufactured Nanoparticles. In ParticleLung Interactions, $2^{\text {nd }}$ Ed.; Gehr, P, Ed.; Informa Healthcare: New York, USA, 2010, pp. 38-59.

44. Schmid, K.; Riediker, M. Use of Nanoparticles in Swiss Industry: A Target Survey. Environmental and Scientific Technology 2008, 42, 2253-2259.

45. Aitken, R.J.; Creely, K.S.; Tran, C.L. Nanoparticles: An occupational hygiene review. Institute of Occupational Medicine, Health and Safety Executive Research Report 2004, 274.

46. Stark, W.J.; Pratsinis, S.E. Aerosol flame reactors for manufacture of nanoparticles. Powder Technology, 2002, 126, 103-108.

47. Raemy, D.O.; Limbach, L.K.; Rothen-Rutishauser, B.; Grass, R.N.; Gehr, P.; Birbaum, K.; Brandenberger, C.; Günther, D.; Stark W.J. Cerium oxide nanoparticle uptake kinetics from the gas-phase into lung cells in vitro is transport limited. European Journal of Pharmaceuticals and. BioPharmaceuticals, Submittedin Press.

48. Kilbourn, B.T. Cerium and Cerium compounds.,In Kirk-Othmer encyclopedia ofchemical technology, $5^{\text {th }}$ Ed.; Seidel, A., Ed.; Wiley Interscience, Hoboken, USA, 2004, Volume 5, pp. 670-692.

49. Reinhardt, K.; Winkler, H. Cerium Mischmetal, Cerium Alloys, and Cerium Compounds.,In Ullmann's encyclopedia of industrial chemistry, $6^{\text {th }}$ Ed.; Wiley- 
VCH Verlag GmbH Co. KGaA, Weinheim, Germany, 2003, Volume 7, pp. 285300 .

50. Kappenberger, L.; Bühlmann, A.A. Lungenveränderungen durch "Seltene Erden". Swiss Medical Weekly 1975, 105.

51. McDonald, J.W. ; Ghio, A.J.; Sheehan, C.E. ; Bernhardt, P.F. ; Roggli, V.L. Rare-Earth (Cerium Oxide) Pneumoconiosis - Analytical Scanning ElectronMicroscopy and Literature-Review. Modern Pathology 1995, 8, 859-865.

52. Pairon, J.C.; Roos, F.; Iwatsubo, Y.; Janson, X.; Billongalland, M.A.; Bignon, J.; Brochard, P. Lung retention of cerium in humans. Occupational and Environmental Medicine 1994, 51, 195-199.

53. Pairon, J.C.; Roos, F.; Sebastien, P.; Chamak, B.; Abdalsamad, I.; Bernaudin, J.F.; Bignon, J.; Brochard, P. Biopersistence of cerium in the human respiratorytract and ultrastructural findings. American Journal of Industrial Medicine 1995, 27, 349-358.

54. Vogt, P.; Spycher, M.A.; Rüttner, J.R. Pneumokoniose durch "Seltene erden" (Cer-Pneumokoniose). Swiss Medical Weekly 1986, 116, 1303-1308.

55. Peteiro-Cartelle, J.; Rodriguez-Pedreira, M.; Zhang, F.; Gil, P.R.; del Mercato, L.L.; Parak, W.J. One example on how colloidal nano- and microparticles could contribute to medicine. Nanomedicine 2009, 4, 967-979.

56. Ghosh, P.; Han, G.; De, M.; Kim, C.K.; Rotello, V.M. Gold nanoparticles in delivery applications. Advanced Drug Delivery Reviews 2008, 60, 1307-1315.

57. Smith, A.M.; Duan, H.; Mohs, A. M.; Nie, S. Bioconjugated quantum dots for in vivo molecular and cellular imaging. Advanced Drug Delivery Reviews 2008, 60, 1226-1240.

58. Petros, R.A.; DeSimone, J. M. Strategies in the design of nanoparticles for therapeutic applications. Nature Reviews Drug Discovery 2010, 9, 615-627.

59. Wagner, A.; Vorauer-Uhl, K.; Katinger, H. Nebulization of liposomal rh-Cu/ZnSOD with a novel vibrating membrane nebulizer. Journal of Lipid Research 2006, 16, 113-125.

60. O’Sullivan, C.K.; Guilbault, G.G. Commercial quartz crystal microbalances theory and applications. Biosensors and Bioelectronics 1999, 14, 663-670.

61. Chen, Y. H.; Tsai, C. Y.; Huang, P. Y.; Chang, M. Y.; Cheng, P. C.; Chou, C. H.; Chen, D. H.; Wang, C. R.; Shiau, A. L.; Wu, C. L. Methotrexate conjugated to gold nanoparticles inhibits tumor growth in a syngeneic lung tumor model. Molecular Pharmacology 2007, 4, 713-722.

62. Brandenberger, C.; Rothen-Rutishauser, B.; Muhlfeld, C.; Schmid, O.; Ferron, G.A.; Maier, K.L.; Gehr, P.; Lenz, A.G. Effects and uptake of gold nanoparticles deposited at the air-liquid interface of a human epithelial airway model. Toxicology and Applied Pharmacology 2010a, 242, 56-65. 
63. Brandenberger, C.; Muhlfeld, C.; Zulqurnain, A.; Lenz, A-G.; Schmid, O.; Parak, W.; Gehr, P.; Rothen-Rutishauser, B. Quantitative evaluation of cellular uptake and trafficking of plain and polyethylene glycol-coated gold nanoparticles. Small 2010b, 6, 1669-1678.

64. Ryan, S.M.; Mantovani, G.; Wang, X.; Haddleton, D.M.; Brayden, D.J. Advances in PEGylation of important biotech molecules: delivery aspects. Expert Opinions in Drug Delivery 2008, 5, 371-383.

65. Knebel, J.W.; Hoffmann, K.; Lodding, H.; Windt, H.; Koch, W.; Aufderheide, M. Development and validation of a semiautomatic system for generation and deposition of sprays on isolated cells of the respiratory tract. Toxicology Mechanisms and Methods 2001, 11, 161-171.

66. Ritter, D.; Knebel, J.W.; Aufderheide, M. In vitro exposure of isolated cells to native gaseous compounds - development and validation of an optimized system for human lung cells. Experimental and Toxicologic Pathology 2001, 53, 373386.

67. Kameyama, S.; Kondo, M.; Takeyama, K.; Nagai, A. Air-exposure causes oxidative stress in cultured bovine tracheal epithelial cells and produces a change in cellular glutathione systems. Experimental Lung Research 2003, 29, 567-583.

68. Pope C. A.; Burnett, R. T.; Thun, M. J.; Calle, E. E.; Krewski, D.; Ito, K.; Thurston, G. D. Lung cancer, cardiopulmonary mortality, and long-term exposure to fine particulate air pollution. Journal of the American Medical Association 2002, 287, 1132-1141.

69. Brandsma, C.A.; Hylkema, M.N.; Luinge, M.A.; Geerlings, M.; Klok, P.A.; Cassee, F.R.; Timens, W.; Postma, D.S.; Kerstjens, H.A. Nitrogen dioxide exposure attenuates cigarette smoke-induced cytokine production in mice. Inhalation Toxicology 2008, 20, 183-189.

70. Chhikara, M.; Wang, S.; Kern, S.J.; Ferreyra, G.A.; Barb, J.J.; Munson, P.J.; Danner, R.L. Carbon monoxide blocks lipopolysaccharide-induced gene expression by interfering with proximal TLR4 to NF-kappaB signal transduction in human monocytes. PLoS One 2009, 4, 12.

71. Sawyer, K.; Mundandhara, S.; Ghio, A.J.; Madden, M.C. The effects of ambient particulate matter on human alveolar macrophage oxidative and inflammatory responses. Journal of Toxicology and Environmental Health, Part A 2010, 73, 4157.

72. Scapellato, M.L.; Lotti, M. Short-term effects of particulate matter: an inflammatory mechanism? Critical Reviews in Toxicology 2007, 37, 461-487.

73. Becker, S.; Mundandhara, S.; Devlin, R.B.; Madden, M. Regulation of cytokine production in human alveolar macrophages and airway epithelial cells in response to ambient air pollution particles: Further mechanistic studies. Toxicology and Applied Pharmacology 2005, 207, 269-275. 
74. Brauner, E.V.; Forchhammer, L.; Moller, P.; Simonsen, J.; Glasius, M.; Wahlin, P.; Raaschou-Nielsen, O.; Loft, S. Exposure to ultrafine particles from ambient air and oxidative stress-induced DNA damage. Environmental Health Perspectives 2007, 115, 1177-1182.

75. Donaldson, K.; Tran, L.; Jimenez, L.A.; Duffin, R.; Newby, D.E.; Mills, N.; MacNee, W.; Stone, V. Combustion-derived nanoparticles: a review of their toxicology following inhalation exposure. Particle and Fibre Toxicology 2005, 2, $10-24$.

76. Pan, C.J.; Schmitz, D.A.; Cho, A.K.; Froines, J.; Fukuto, J.M. Inherent redox properties of diesel exhaust particles: catalysis of the generation of reactive oxygen species by biological reductants. Toxicological Sciences 2004, 81, 225232.

77. Xiao, G.G.; Wang, M.; Li, N.; Loo, J.A.; Nel, A.E. Use of proteomics to demonstrate a hierarchical oxidative stress response to diesel exhaust particle chemicals in a macrophage cell line. Journal of Biological Chemistry 2003, 278, 50781-50790.

78. Kittelson, D.B.; Kadue, P.A.; Scherrer, H.C.; Lovrien, R. Characterization of diesel particles in the atmosphere. CRC project AP-1 Final Report 1988, submitted to Coordinating Research Council.

79. Ochs, M.; Weibel, E.R. Functional design of the human lung for gas exchange. In Fishman's Pulmonary Diseases and Disorders, $1^{\text {st }}$ Ed.; Fishman, A.P., Elias, J.A., Fishman, J.A., Grippi, M.A., Senior, R.M., Pack, A.I. Eds.;.Mc Graw Hill, New York, USA, 2008; pp. 23-69.

80. Papaioannou, E.; Konstandopoulos, A.G.; Morin, J.P.; Preterre, D. A selective particle size sampler suitable for biological exposure studies of diesel particulate. SAE International 2006.

81. Gehrig, R.; Hueglin, C.; Devos, W.; Hofer, P.; Kobler, J.; Stahel, W.A.; Baltensperger, U.; Monn, C. Contribution of road traffic to ambient fine particle concentrations (PM10) in Switzerland. International Journal of Vehicle Design 2001, 27, 1-4,.55-64.

82. Gehrig, R.; Hill, M.; Buchmann, B.; Imhof, D.; Weingartner, E.; Baltensperger, U. Separate determination of PM10 emission factors of road traffic for tailpipe emissions and emissions from abrasion and resuspension processes. International Journal of Environmental Pollution 2004, 22, 3, 312-325.

83. Wilson, M.R.; Lightbody, J.H.; Donaldson, K.; Sales, J.; Stone, V. Interactions between ultrafine particles and transition metals in vivo and in vitro. Toxicological Applications in Pharmacology 2002, 184, 172-179.

84. Donaldson, K.; Stone, V.; Borm, P.J.; Jimenez, L.A.; Gilmour, P.S.; Schins, R.P.; Knaapen, A.M.; Rahman, I.; Faux, S.P.; Brown, D.M.; MacNee, W. Oxidative stress and calcium signaling in the adverse effects of environmental particles (PM10). Free Radical Biology and Medicine 2003, 34, 1369-82. 
85. Rauterberg-Wulff, A.; Beitrag des Reifen- und Bremsabriebs zur Russemission an Strassen., In Umwelttechnik, VDI-Verlag, Düsseldorf, Germany, 1998; 202, 15.

86. Eriksson, M.; Jacobson, S. Tribological surfaces of organic brake pads. Tribology International, 2000, 33, 817-827.

87. Garg, B.D. Brake wear particulate matter emissions,. Environmental and Scientific Technolology 2000, 34, 4463-4469.

88. Smith, H. Human respiratory tract model for radiological protection. A report of a Task Group of the International Commission on Radiological Protection. Annals of the ICRP 1994, 24, 1-482.

89. Riediker, M.; Devlin, R.B.; Griggs, T.R.; Herbst, M.C.; Bromberg, P.A.; Williams, R.W.; Cascio, W.E. Cardiovascular effects in patrol officers are associated with fine particulate matter from brake wear and engine emissions. Particle and Fibre Toxicology 2004, 1, 2.

90. Perret, V.; Huynh, C.K.; Droz, P.O.; Vu Duc, T.; Guillemin, M.P. Assessment of occupational exposure to diesel fumes - parameter optimization of the thermal coulometric measurement method for carbon. Journal of Environmental Monitoring 1999, 1, 367-372.

91. Occupational Safety and Health Administration (OSHA). OSHA analytical method no. ID-121, metal and metalloid particulates in workplace atmospheres (atomic absorption) 2002.

92. Sanders, P.G.; Xu, N.; Dalka, T.M.; Maricq, M.M. Airborne brake wear debris: size distributions, composition, and a comparison of dynamometer and vehicle tests. Environmental Scientific Technology 2003, 37, 4060-4069.

93. Gasser, M.; Riediker, M.; Mueller, L.; Perrenoud, A.; Blank, F.; Gehr, P.; Rothen-Rutishauser, B. Toxic effects of brake wear particles on epithelial lung cells in vitro. Particle and Fibre Toxicology 2009, 6-30.

94. Rothen-Rutishauser, B.; Mueller, L.; Blank, F.; Brandenberger, C.; Muehlfeld, C.; Gehr, P.; A newly developed in vitro model of the human epithelial airway barrier to study the toxic potential of nanoparticles. Alternatives to Animal Experimenation 2008, 25, 191-196.

95. Alfaro-Moreno, E.; Nawrot, T.S.; Vanaudenaerde, B.M.; Hoylaerts, M.F.; Vanoirbeek, J.A.; Nemery, B.; Hoet, P.H.M. Co-cultures of multiple cell types mimic pulmonary cell communication in response to urban $\mathrm{PM}_{10}$. European Respiratory Journal 2008, 32, 1184-1194.

96. Bhabra, G.; Sood, A.; Fisher, B.; Cartwright, L.; Saunders, M.; Evans, W.H.; Surprenant, A.; Lopez-Castejon, G.; Mann, S.; Davis, S.A.; Hails, L.A.; Ingham, E.; Verkade, P.; Lane, J.; Heesom, K.; Newson, R.; Case, C.P. Nanoparticles can cause DNA damage across a cellular barrier. Nature Nanotechnology 2009, 4, 876-883. 
97. Abe, S.; Takizawa, H.; Sugawara, I.; Kudoh, S. Diesel exhaust (DE)-induced cytokine expression in human bronchial epithelial cells: a study with a new cell exposure system to freshly generated DE in vitro. American Journal of Respiratory Cellular and Molecular Biology 2000, 22, 296-303.

98. Cheng, M.D.; Malone, B.; Storey, J.M. Monitoring cellular responses of engineemitted particles by using a direct air-cell interface deposition technique. Chemosphere 2003, 53, 237-243.

99. de Bruijne, K.; Ebersviller, S.; Sexton, K.G.; Lake, S.; Leith, D.; Goodman, R. et al. Design and testing of Electrostatic Aerosol in Vitro Exposure System (EAVES): an alternative exposure system for particles. Inhalation Toxicology, 2009, 21, 91-101.

100.Holder, A.L.; Lucas, D.; Goth-Goldstein, R.; Koshland, C.P. Inflammatory response of lung cells exposed to whole, filtered, and hydrocarbon denuded diesel exhaust. Chemosphere, 2007, 70, 13-19.

101.Holder, A.L.; Lucas, D.; Goth-Goldstein, R.; Koshland, C.P. Cellular response to diesel exhaust particles strongly depends on the exposure method. Toxicological Sciences, 2008. 103,108-115.

102.Komori, K.; Murai, K.; Miyajima, S.; Fujii, T.; Mohri, S.; Ono, Y.; Sakai, Y. Development of an in vitro batch-type closed gas exposure device with an alveolar epithelial cell line, A549, for toxicity evaluations of gaseous compounds. Analytical Sciences 2008, 24, 957-962.

103.Morin, J.P.; Fouquet, F. ; Monteil, C. ; Le Prieur, E. ; Vaz, E. ; Dionnet, F. Development of a new in vitro system for continuous in vitro exposure of lung tissue to complex atmospheres: application to diesel exhaust toxicology. Cellular and Biological Toxicology 1999, 15, 143-152.

104.Le Prieur, E. ; Vaz, E. ; Bion, A. ; Dionnet, F. ; Morin, J.P. Toxicity of diesel engine exhausts in an in vitro model of lung slices in biphasic organotypic culture: induction of a proinflammatory and apoptotic response. Archives of Toxicology 2000, 74, 460-466.

105.Bion, A. ; Fal, M. ; Gouriou, F. ; Le Prieur, E. ; Dionnet, F. ; Morin, J.P. Biphasic culture of rat lung slices for pharmacotoxicological evaluation of complex atmospheres. Cellular and Biological Toxicology 2002, 18, 301-314.

106.Morin, J.P.; Hasson, V.; Fall, M.; Papaioanou, E.; Preterre, D.; Gouriou, F.; et al. Prevalidation of in vitro continuous flow exposure systems as alternatives to in vivo inhalation safety evaluation experimentations: outcome from MAAPHRIPCRD5 research program. Experimental and Toxicological Pathology 2008, 60, 195-205.

107.Knebel, J.W.; Ritter, D.; Aufderheide, M. Exposure of human lung cells to native diesel motor exhaust - development of an optimized in vitro test strategy. Toxicology In Vitro 2002, 16, 185-192. 
108. Aufderheide, M.; Ritter, D.; Knebel, J.W.; Scherer, G. A method for in vitro analysis of the biological activity of complex mixtures such as sidestream cigarette smoke. Experimental and Toxicological Pathology 2001, 53, 141-152.

109.Mulhopt, S.; Diabate, S.; Krebs, T.; Weiss, C.; Paur, H-R. Lung toxicity determination by in vitro exposure at the air liquid interface with an integrated online dose measurement. Journal of Physics (Conference Series) 2009, 170, 012008.

110.Bitterle, E.; Karg, E.; Schroeppel, A.; Kreyling, W.G.; Tippe, A.; Ferron, G.A.; Schmid, O.; Heyder, J.; Maier, K.L.; Hofer, T. Dose-controlled exposure of A549 epithelial cells at the air-liquid interface to airborne ultrafine carbonaceous particles. Chemosphere 2006, 65, 1784-1790.

111.Tippe, A.; Heinzmann, U.; Roth, C. Deposition of fine and ultrafine aerosol particles during exposure at the air.cell interface. Aerosol Sciences 2002, 33, 207218.

112.Savi, M.; Kalberer, M.; Lang, D.; Ryser, M.; Fierz, M.; Gaschen, A.; Ricka, J.; Geiser, M. A novel exposure system for the efficient and controlleddeposition of aerosol particles onto cell cultures. Environmental and Scientific Technology 2008, 42, 5667-5674.

113.Clift, M.J.D.; Gehr, P.; Rothen-Rutishauser, B. In vitro Testing for Nanotoxicology: A valid alternative? Archives of Toxicology, In Press

(C) 2011 by the authors; licensee Insciences Journal.

Open Access article under the terms and conditions of the Creative Commons Attribution Non-Commercial License 3.0 Unported 